\title{
Time to re-engage psychiatric drug discovery by strengthening confidence in preclinical psychopharmacology
}

\author{
Mark David Tricklebank ${ }^{1}$ (D) Trevor W. Robbins $^{2} \cdot$ Camilla Simmons $^{1} \cdot$ Erik H. F. Wong $^{3}$ \\ Received: 25 June 2020 / Accepted: 4 February 2021 / Published online: 10 March 2021 \\ (C) The Author(s), under exclusive licence to Springer-Verlag GmbH Germany, part of Springer Nature 2021
}

\begin{abstract}
Background There is urgent need for new medications for psychiatric disorders. Mental illness is expected to become the leading cause of disability worldwide by 2030 . Yet, the last two decades have seen the pharmaceutical industry withdraw from psychiatric drug discovery after costly late-stage trial failures in which clinical efficacy predicted pre-clinically has not materialised, leading to a crisis in confidence in preclinical psychopharmacology.

Methods Based on a review of the relevant literature, we formulated some principles for improving investment in translational neuroscience aimed at psychiatric drug discovery.

Results We propose the following 8 principles that could be used, in various combinations, to enhance CNS drug discovery: (1) consider incorporating the NIMH Research Domain Criteria (RDoC) approach; (2) engage the power of translational and systems neuroscience approaches; (3) use disease-relevant experimental perturbations; (4) identify molecular targets via genomic analysis and patient-derived pluripotent stem cells; (5) embrace holistic neuroscience: a partnership with psychoneuroimmunology; (6) use translational measures of neuronal activation; (7) validate the reproducibility of findings by independent collaboration; and (8) learn and reflect. We provide recent examples of promising animal-to-human translation of drug discovery projects and highlight some that present re-purposing opportunities.

Conclusions We hope that this review will re-awaken the pharma industry and mental health advocates to the opportunities for improving psychiatric pharmacotherapy and so restore confidence and justify re-investment in the field.
\end{abstract}

Keywords Psychiatric drug discovery $\cdot$ New medications $\cdot$ Psychiatric disorder $\cdot$ Systems neurosciencese

\section{Introduction}

The World Health Organisation (WHO) estimates that untreated mental disorders account for $13 \%$ of the total global burden of disease and that by 2030 depression alone will be the leading cause of disability around the world, outstripping heart disease, cancer and HIV (Patel et al. 2018). This "time bomb" might have been hastened by the COVID-19

Mark David Tricklebank tricklebank.mark@kcl.ac.uk

1 Centre for Neuroimaging Sciences, Institute of Psychiatry Psychology and Neuroscience, King's College, London, UK

2 Department of Psychology and Behavioural and Clinical Neuroscience Institute, University of Cambridge, CB23EB, Cambridge, UK

3 Department of Psychiatry, University of British Columbia, Vancouver, Canada pandemic, whereby the global mitigation strategy of social distancing and isolation, compounded by high anxiety, fear of uncertainties, and emerging cytokine-based pathologies conspires to create a "perfect storm" of mental ill health. The dearth of novel and more efficacious treatment options in psychiatry has been attributed to a limited understanding of the biological basis of mental disorders. But the pessimism for future success may be unwarranted.

\section{Optimism for new treatment options}

The announcement in 2019 by the US Food and Drug Administration (FDA) of approvals for new interventions for treatment-resistant depression (S-ketamine and vagal stimulation) and postpartum depression (brexanolone) demands attention as these interventions open a new frontier in treatment options for difficult-to-treat depression (Cristea and Naudet 2019). Brexanolone (or allopregnanolone) was 
discovered as a breakdown product of progesterone and deoxycorticosterone that amplifies GABA-activated chloride ion currents (Kose and Cetin 2017). These metabolites fluctuate during times of stress and during the menstrual cycle (Penalver Bernabe et al. 2020). Allopregnanolone increases during pregnancy and then declines after birth, it being thought that this drop triggers depression (Cristea and Naudet 2019).

The motivation to test the potential antidepressant effects of ketamine (Krystal et al. 2019) was based on work on the psychosis-inducing effects of ketamine that led Krystal et al. to think that it was more likely that the pathophysiology of depression resides in the intrinsic circuitry of the cortex and limbic system where glutamate and GABA are the predominant neurotransmitters rather than simply monoaminergic influences on this circuitry. Krystal et al. were aware of the preclinical studies of Trullas and Skolnick (1990), suggesting that NMDA receptor antagonists have antidepressant-like effects in animals subjected to inescapable stress and decided to test the hypothesis clinically. Ketamine was found to produce a rapid profound and surprisingly durable antidepressant effect that was replicated in treatment-resistant major depression (Zarate Jr. et al. 2006). The effects were temporally dissociated from the brief acute behavioural effects of the drugs and led Krystal et al. to state that "substances capable of reducing neurotransmission at the NMDA receptor complex may represent a new class of antidepressants" (Krystal et al. 2019).

It is interesting that the initial development of MK-801 was based on its anticonvulsant and anxiolytic effects in rodents (Clineschmidt 1982) and later in monkeys (Rupniak et al. 1993). Based on these findings, and the the behavioural response to glutamatergic agents in inescapable stress paradigms led Trullas and Skolnick (1990) to conclude "that pathways subserved by the NMDA subtype of glutamate receptors are involved in the pathophysiology of affective disorders and may have heuristic value".

Emerging developments of innovative agents include new insights into preclinical pharmacology, engagement of translational approaches, novel routes of delivery and treatment settings, and rapid onset of drug action. The latter served a long unmet clinical need so far often achieved serendipitously rather than by design. The finding that treatment response to ketamine is related to the plasma concentration of D-serine, an agonist at the glycine modulatory site on the NMDA receptor (Singh et al. 1990), raises the possibility that treatment could be personalised by tailoring to this biomarker or by manipulating plasma D-serine concentration (Moaddel et al. 2015). In reflecting on these and other innovative discoveries, we highlight here how they have informed us about the future challenges and opportunities in biological psychiatry research. We ask what some of the new areas of focus are that we should be addressing, and how will these findings drive our thinking on new treatment options and translational psychopharmacology for global mental disorder management. What should we be doing differently for psychiatric drug discovery and development?

\section{Reflection on a hiatus}

With just a few notable exceptions, most of the US-, Japanand EU-based pharmaceutical companies have now withdrawn resources from psychiatric drug discovery, mainly because of the many costly late-stage failures where the clinical efficacy, predicted preclinically for a novel drug, has not materialised (Sarter and Tricklebank 2012; Wong et al. 2010). It has been argued previously that this is most likely because of a failure to apply "systems neuroscience mapping" to establish linkages between molecular and cellular mechanisms and measures of neuronal circuit function (Sarter and Tricklebank 2012). Systems neuroscience mapping is here defined as the use of homology to make triangulating inferences about relationships between animal and human studies in terms of common functional neural circuitry including neurotransmitters. We provide several examples of how risky decisions have been made on selected molecular mechanisms and suggest eight guiding principles that if followed will enhance the translational validity of preclinical psychopharmacology and provide the essential deep understanding of the relationship between target action measured preclinically and its mapping to clinical phenotypes. If this failure is not understood it will continue to undermine confidence for when companies deem that it is safe to "get back into the water" (Sarter and Tricklebank 2012; Brady et al. 2019).

We illustrate in Fig. 1 how these eight principles can be integrated to support a drug discovery pipeline, noting that these should act as a general guide to thinking rather than as a specific road map. Different problems may require different configurations of these principles, and it may not be necessary to deploy them all in every instance.

This review suggests that renewed confidence in preclinical psychopharmacology is justified if a systems neuroscience approach is taken and provides examples of how this has been achieved. These insights, if effectively adopted, would improve decision making to a point allowing resource reinvestment that would satisfy business leaders and scientists alike. This paper will also show that many preclinical-clinical translational principles for psychiatric drug discovery exist and offers some guidance on how we can begin to restore confidence before the skill base is irreparably damaged or even lost. With the availability of functional neuroimaging and well-designed psychological paradigms that can be readily adapted for use with rodents in translation mode, it is now possible to accurately model, quantify and identify the neuronal mechanisms underlying many aspects of psychiatric symptomatology. 
The 8 Principles; How they work in Theory

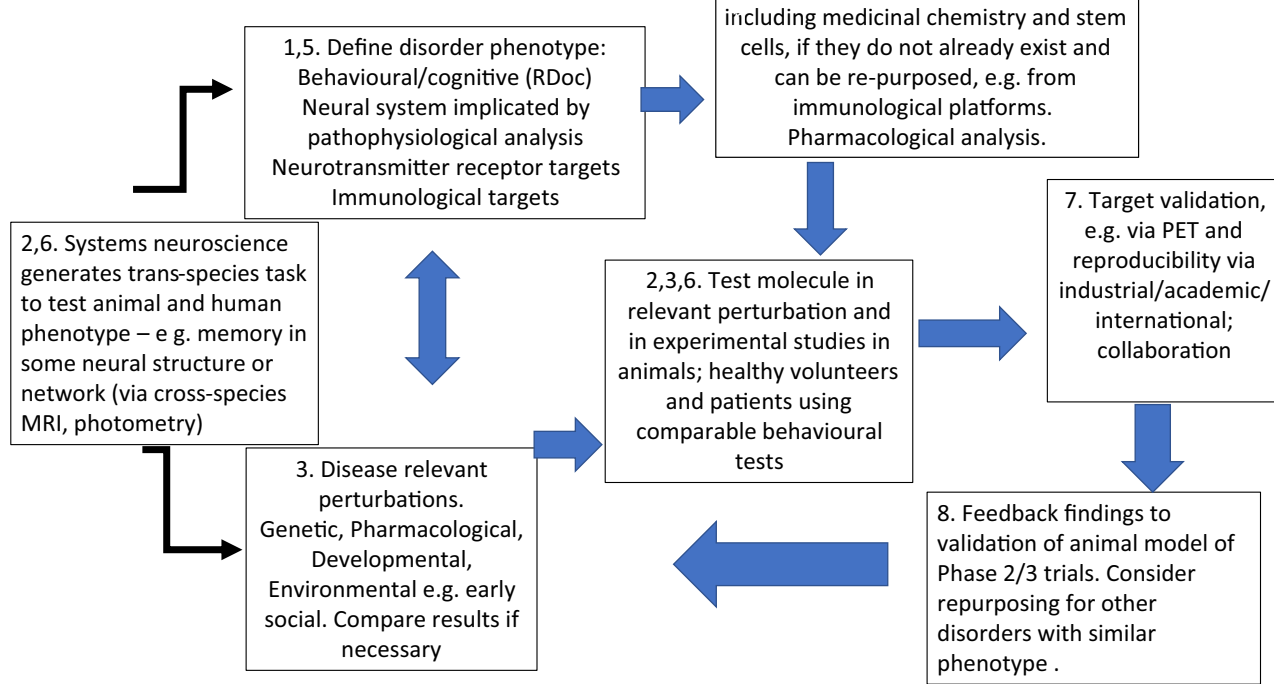

Fig. 1 Schematic diagram to illustrate how in theory the 8 principles (identified by digits) might enhance CNS drug discovery (when applied in the sequence indicated by arrows, from left to right). Basic neuroscience feeds into the definition of disease phenotypes that define targets, and the generation of disease-relevant perturbations. Test molecules are generated from a variety of platforms including medicinal

\section{Principle 1: consider incorporating the NIMH Research Domain Criteria (RDoC) approach}

This recent initiative has challenged the traditional approach to the diagnosis of mental health conditions based on symptom scores which has problems with heterogeneity and deals poorly with comorbidity (Cuthbert and Insel 2013). It seeks to identify dimensions of neurobiology and observable behaviour from an understanding of the biology of the broad domains of dysfunction that are common to psychopathology and are commonly involved across our currently accepted diagnoses (Insel et al. 2013). The functional domains are largely developed from the accumulated understanding and analysis of human and animal bio-behavioural data, by splitting behaviour into broad positive valence (reward responsiveness) and negative valence (acute threat, potential threat, fear and anxiety) systems. Cognitive systems are thought of in terms of such constructs as visual and auditory perception, learning, memory, and cognitive control. The aim is to understand the neurobiology of the elements that constitute the behavioural repertoire, much as there is a need to understand all the bodily elements that control the cardiovascular system that allow the control of its functional parameters within an optimal range to ensure survival.

Support for this concept has been provided by employing a comprehensive evaluation of psychiatric symptoms in 999 youths (Xia et al. 2018). Impressively, along with identifying four dimensions of psychopathology: psychosis, fear, mood and externalising behaviours (problems directed toward the external environment), they went on to demonstrate, using chemistry. Molecules are tested in animal and humans using translational methods and paradigms. Targets are validated and clinical efficacy tested via collaborative studies. Results of studies are fed back to validate, or otherwise, the methods employed, or the molecule tested, or its clinical target

resting state functional imaging and a novel machine learning multivariate analysis, that the four dimensions correlated with distinct patterns of functional connectivity. Loss of network segregation between the default mode network and executive network emerges as a common feature across all dimensions. The findings were replicated within the same study in an independent data set of 336 individuals. The revelation of the high degrees of comorbidity that exist between mental disorders, and the development of neuroimaging techniques that associate these domains with specific patterns of network connectivity, allows the starting point of psychiatric drug discovery to shift away from attempts to understand disease pathology only. RDoC inverts this process and puts basic science as the starting point and disorders are considered as disruptions of the normal range of operation within each domain (Xia et al. 2018). Connectivity related to mood and psychosis becomes more prominent with development while sex differences are present for connectivity related to mood and fear.

Adopting a similar approach, a prominent feature of the human brain's global architecture is the anti-correlation of default mode versus task positive systems (Anticevic et al. 2012). Administration of the psychotomimetic agent ketamine disrupts the reciprocal relationship between these systems in terms of task dependent activation and connectivity during performance of a delayed working memory task. But what of the global functional connectivity in psychosis? Using the same functional imaging approach, Salomon et al. (2011) measured functional connectivity in schizophrenic patients and healthy controls during two different tasks, plus a rest condition, revealing a striking connectivity decrease in 
patients compared to the controls. In the task condition, weaker connectivity was specific to the cortex not active during the task. In the rest condition the difference between patients and controls was larger.

Comorbidity analyses reveal that many mental health problems share an underlying cause; the " $p$ " factor (Hammerschlag et al. 2020). The $p$ factor is analogous to Spearman's $g$ factor for general intelligence, an overarching cognitive capacity that emerged from factor analysis of children's ability that reflects the fact that children good at one task tend to be good at others. Adopting a similar approach, Lahey et al. (2012) analysed the diagnoses of 30,000 people over a 3-year period and found that the observed patterns of illness were best explained by a general tendency towards mental health conditions. Selzam et al. (2018) coined the term $p$ factor to describe an individual's broad susceptibility to mental health problems. The $p$ factor can explain puzzling patterns of mental health conditions within families. Twin studies have estimated the heritability of schizophrenia at $80 \%$, and major depression at $45 \%$, but having a parent or sibling diagnosed with a given condition does not simply increase the odds of experiencing that condition, but also increases the odds of one being diagnosed with a different condition. If a parent has schizophrenia, the risk of developing bipolar disorder doubles and vice versa.

The neural and psychological nature of the $p$ factor is still being elucidated. As $g$ depends on the dynamic reorganisation of brain networks, modifying their topology and community structure in the service of system-wide flexibility and adaptation (Barbey 2018), the $p$ factor may also be equally dependent on the same global connectivity pattern changes and might help in relating the domains of psychopathology possibly illuminating the links that determine why suffering psychosis raises the risk of also suffering cognitive impairment. There is evident overlap of $g$ with neural networks that engage 'fronto-executive' function, and much is known about the pharmacological modulation of this system - one prominent example being via drugs affecting the ascending catecholamine (ie dopamine and noradrenaline) systems. Drugs such as Ritalin (methylphenidate) appear to enhance cognitive effort, i.e. enhancing motivation to engage executive functions such as working memory (Westbrook et al. 2020) as well as normalising brain activation and connectivity in ADHD (Rubia et al. 2009) and therefore may have global effects that ameliorate the $\mathrm{p}$ factor.

In order to provide clues of possible targets it is necessary to employ animal models that reflect some part of the known aetiological factors of the psychiatric disorder of interest. We are aware that these are not always understood sufficiently at a mechanistic level to provide an optimal disease model but taking the $\mathrm{RDoC}$ approach removes this necessity. In fact, the $\mathrm{RDoC}$ approach encourages the view that complex disorders may need to be treated with more than one medication to target the heterogeneity of the presentation of the condition and the heterogeneity of the underlying pathology.

We acknowledge that the further application of RDoC constructs will require a change in the mindset of regulators and payors who still adhere to traditional diagnostic criteria for approvals and reimbursements. A good example is the NIMH Fast-Fail initiative anhedonia study with the $\mathrm{K}$-opioid receptor antagonist, JNJ-67953964 (Krystal et al. 2020; Germine et al. 2019). This was framed as an antidepressant study because that is what the FDA would likely approve. However, the compound significantly reduced anhedonia without impacting depression scores overall and unless anhedonia is recognised by the regulatory agencies as an indication, the treatment might not then be made available. Researchers are to some degree already comfortable with the $\mathrm{RDoC}$ concept, but progress can only be made if regulators recognise $\mathrm{RDoC}$ constructs as targets for drug development.

\section{Principle 2: engage the power of translational and systems neuroscience approaches}

A key point of improvement for preclinical testing is to develop and use rodent behavioural assays that are as close as possible to those used clinically to identify and quantify the behavioural symptomatology of interest. As an example, the stop signal reaction time is a sophisticated go/no-go measure of impulsivity that can be modulated clinically and preclinically by the selective norepinephrine reuptake inhibitor atomoxetine (Chamberlain et al. 2009; Chamberlain and Sahakian 2007). A very similar task to that used in humans involves the same initial development in rats of a pre-potent response of pressing two levers in sequence to obtain food, whilst having to withhold the second response on $20 \%$ of the trials when a stop signal auditory tone is presented. Local micro-infusion of atomoxetine into the lateral orbitofrontal and dorsal prelimbic cortex reduced the stop signal reaction time (Bari et al. 2011), i.e. reduced impulsivity. Similar effects have been shown following acute systemic doses of atomoxetine in humans (Chamberlain et al. 2009). In human functional imaging experiments, short stop signal reaction times, or more efficient response inhibition, following atomoxetine treatment, was associated with greater activation in the homologous inferior frontal cortex ( $\mathrm{Li}$ et al. 2006; Chamberlain et al. 2009). Translational validity of the behavioural task used to quantify psychiatric symptoms can thus be achieved if the task can be shown to involve homologous brain regions across species.

A further example of an anatomically well-defined test of cognitive flexibility is the rodent version of the Wisconsin Card Sorting Test (WCST), in which a subject has to learn to sort cards according to rules based on the colour, set or number of playing cards (Birrell and Brown 2000). This 
human task has been decomposed into its elements in the CANTAB intra-dimensional/extra-dimensional (IDED) setshifting test, which has been administered to both human patients and monkeys (Keeler and Robbins 2011). This test measures abstract rule learning about particular perceptual features of visual stimuli, such as their shape, on the basis of trial-anderror-learning, the ability to shift to an alternative rule when the feedback changes and the ability to reverse the reward and punishment contingencies of a particular rule. Studies in the marmoset monkey (Dias et al. 1996) have indicated that whereas damage to the lateral prefrontal cortex impairs shifting of abstract rule learning, reversal learning is impaired by lesions of the orbitofrontal cortex (OFC). Analogous findings have been found in human imaging and patient studies of the WCST (Kramer et al. 2007) and the CANTAB IDED task (Vaghi et al. 2008; Leeson et al. 2009).

Trial and error learning is also the basis of the rodent version of the task which is similarly dependent on two prefrontal cortex regions; the orbitofrontal cortex (reversal) and the medial prefrontal cortex (abstract rule shift), as indicated by lesion studies (Kramer et al. 2007). In the rodent assay, the animal initially has to form an attentional set on the basis of discrimination of the odours of one of two differentially scented pots (e.g. thyme vs. cumin) in which food has been buried in contrasting textured media (e.g. stones vs sawdust) by digging for food (Birrell and Brown 2000). Reversal learning is tested by swapping whether thyme or cumin is the correct odour, whereas extra-dimensional shifting occurs when the relevant rule is to respond to the texture of the medium rather than its odour. Deficits in both reversal and extra-dimensional set shifting have been shown to be prominent aspects of cognitive impairment in schizophrenia (Leeson et al. 2009), and are dependent on homologous brain regions in rodents, monkeys and man (Keeler and Robbins 2011).

\section{Translational value of rodent behaviour}

A further contributor to this reluctance to re-engage is scepticism that animal physiology can inform mechanisms underlying human behaviour and, in particular, that rodents are capable of exhibiting behavioural analogues of what had previously been thought to reflect uniquely human attributes. It is conceivable that the desire to avoid facile anthropomorphic interpretations of animal behaviour has contributed to this mistrust. But such views have been clearly demonstrated to be untrue in situations where the behaviour has also been shown to involve homologous brain circuitry in animals and man. An impressive example is the demonstration that rats can be shown to adopt empathic decision making when they observe others being subjected to foot-shock (HernandezLallement et al. 2020). The experiment involved instrumental conditioning in which rats were trained to press one of two levers for food reward. Evidence of empathic decision- making was demonstrated when a second lever delivered equal amounts of food but also foot-shock to a neighbouring rat. When allowed to choose between levers, the animals showed a clear preference for avoiding the lever associated with delivering pain to another. This reaction is recognised in human psychology as harm aversion and is associated with activation of the anterior cingulate cortex (ACC). Reducing activity in the ACC by injection of baclofen abolished the harm aversion response in the rat (Marsh et al. 2013) showing conservation of neural mechanisms.

The second example is in similar vein using the highly social monogamous prairie vole. Burkett et al. (2016) demonstrated that the animal shows consolatory behaviour most commonly associated with humans and great apes in that, having witnessed the exposure to stress of a cage mate, the observer animal greatly increases partner-directed grooming towards familiar conspecifics, but not to strangers that have experienced an unobserved stressor. Exposure to the stressed cage mate increases activity in the ACC and the behaviour is blocked when an oxytocin receptor antagonist is infused into this area, again showing conserved neural mechanisms between prairie vole and man. Further evidence supporting this view is given by Uysal et al. (2020).

Rats are also capable of expressing the human tendency to place greater value on the things for which we work hardest, a phenomenon attributed by psychologists to reflect a state of cognitive dissonance or psychological discomfort that occurs when there is a discrepancy between a person's attitude and their actions. Thus, it has been found that rats place more value on a sucrose reward when it follows high effort (Lydall et al. 2010). Rats were trained to press a lever for food reward and the effort required was manipulated by varying the number of lever presses the animal had to make before reward was delivered. The value of a liquid sucrose reward was estimated by examination of palatability via microstructural analysis of licking behaviour during ingestion (Lydall et al. 2010; Dwyer 2012). There is also growing interest and capability in measuring subtle changes in social behaviour in rodents, as a consequence of increased attention to treatment of psychiatric conditions where impairments in social behaviour are found (Nardou et al. 2019).

Equally impressive is the discovery of the role played by the GNPTAB gene products, the N-acetylglucosamine-1phosphate transferase $\alpha$ and $\beta$ subunits, in the common neurodevelopmental disorder of stuttering (Han et al. 2019). Unlike the relatively minor effects of copy number variants (CNVs) engineered as significant risk factors for the development of schizophrenia (see below), genetic engineering of the human stuttering mutation into mice resulted in deficits in the flow of ultrasonic vocalisations very similar in pattern to stuttering deficits in humans. Histological examination indicated that a deficit in astrocytes in white matter tracts, particularly in the corpus callosum, may lead to a deficit in 
interhemispheric connectivity in stuttering. Mice carrying mutations in the FoxP2a gene mutated in human developmental dyslexia, also have abnormalities in a range of vocalisation phenotypes (Fujita-Jimbo and Momoi 2014), strongly supporting the view that mice can serve as a valid model for investigating central nervous system functions, even those considered to be uniquely human in nature.

These investigations open up behaviours thought primarily beyond the cognitive capacity of rodents, and that can be pharmacologically manipulated (Uysal et al. 2020). The tendency of some to dismiss rodent-based neuroscience as irrelevant to the mechanisms underlying human brain dysfunction are closing their eyes to a source of knowledge that is highly relevant and able to inform our understanding of the molecular events that underlie human brain function and more importantly, human brain dysfunction (Markou et al. 2009).

Although animal models have often received considerable blame for failing to predict the outcome of psychiatric clinical trials, it has also been pointed out that experimental medicine studies across the spectrum of clinical disorders in volunteers and patients perform no better in this regard. It has been argued that one way of achieving this is to implement the philosophy about animal behavioural testing mentioned above, that it should show some degree of commonality with human behavioural and cognitive tests (as in the CANTAB and other test batteries (Barnett et al. 2016). Some translation of these relatively objective behavioural tests should then be employed in phases 2 and 3, if not replacing, at least paralleling, the clinical scales used for evaluating drug outcomes. Such scales are often based on self-report of subjective assessment of symptoms by the psychiatrist and may lack sensitivity, as well as failing to reflect what has been established about drug actions in pre-clinical investigations. What must be improved is the vertical translation between animal studies, mechanismbased human findings and classical clinical outcomes.

\section{Principle 3: use disease-relevant experimental perturbations}

Of course, it is important that assumptions about cognitive testing in animals are tested and shown to be valid, in that similarities in behaviour are shown to involve homologous brain regions and circuitry in performance within the normal range. While the $\mathrm{RDoC}$ approach obviates the need for animal models of disease, the range of behaviour within a particular psychopathological domain may remain hidden unless the extremes of the range can be studied and quantified. If, for example, the domain of interest is psychosis and there is evidence that psychotic symptoms are seen in man when glutamate release is stimulated by administration of ketamine in the prefrontal cortex (Stone et al. 2008) so leading to impairment of working memory tasks, then it is logical to test the ability of a compound to reverse those changes rather than seek to see an improvement in performance within the normal range.

The NMDA receptor antagonist phencyclidine (PCP) induces many symptoms reminiscent of schizophrenia in healthy volunteers (Krystal et al. 2002; Teixeira et al. 2017). Indeed, a number of suspected cases of schizophrenia are actually a consequence of an autoimmune inflammatory process in which the antibodies formed are directed at the NMDA receptor and thus act like an NMDA receptor antagonist such as PCP or ketamine (Teixeira et al. 2017). There is no doubt that NMDA receptor antagonists have proved extremely useful tools in understanding the pathophysiology of psychosis. In healthy volunteers, acute treatment with ketamine rapidly induces behaviours associated with the negative and positive symptoms of schizophrenia (Krystal et al. 2002) and disturbs cognitive functioning, attentional set shifting, and both delayed and immediate memory recall changes that are associated with the ketamine-induced release of glutamate (Deakin et al. 2008; Abdallah et al. 2018; Krystal et al. 1994).

For schizophrenia, it is evident that there are diseaserelated genetic, developmental, as well as neural and neurochemical aspects of its pathophysiology that can be reproduced in experimental animals (Robbins and Moore 2008). While the perfect combination of these putative factors has yet to be established, comparison of different models, preferably by collaboration and co-operation across laboratories, can begin to approach this goal by focussing on a domain of psychopathology and its underlying circuitry that obviates the need for a model that combines all these factors. The value of comparing models can be seen from the recent study by Scarpa et al. (2020) which showed that three distinct murine models of stress reproduced different aspects of the genetic expression of human major depressive disorder in the medial frontal cortex and nucleus accumbens. The demonstration shows the difficulty of capturing an entire mental disorder in a single model and emphasises their multifaceted as well as polygenic heterogeneous and co-morbid nature which will likely require a multimodel treatment approach.

Disease model perturbations such as those induced by the DNA-alkylating agent methylazoxymethanol acetate (MAM) administered to pregnant dams on embryonic day 17 (E17) provide a neurodevelopmental aspect to a model of schizophrenia (Robbins and Moore 2008) that is reliable at the neurobiological level with six different laboratories all reporting similar neuroanatomical differences especially in the hippocampus (Howe et al. 2015). Moreover, MAM treatment impacted a battery of ventral and dorsal hippocampal-dependent memory tasks (Arguello et al. 2010). Spatial reference memory deficits in the water-maze spatial memory task were replicated in two separate MAM E17 cohorts (Gastambide et al. 2015).

Deficits have also been found in reversal learning and extra-dimensional attentional set shifting that were completely 
remediated by an mGluR5 receptor positive allosteric modulator (PAM) consistent with a demonstrated loss of mGluR5 receptors in the predicted regions of the prefrontal cortex as a consequence of the MAM pre-treatment (Gastambide et al. 2012). However, the effect size and consequent power analysis rendered the need for sample sizes to be very large to ensure reproducibility and was ultimately considered excessive for the resources available for its routine use in a drug discovery programme.

Unfortunately, the mGluR5 receptor PAMs also cause adverse effects such as cortical necrosis and this explains why the drug has not progressed to clinical trials. But this does not take away the valuable insights gained in the preclinical work on this class of agents (Parmentier-Batteur et al. 2014). In $\mathrm{RDoC}$ terminology, mGluR5 is clearly capable of modulating the cognitive impairment associated with psychosis and can ameliorate the cognitive impairment associated with NMDA receptor antagonists and aspects of cognitive flexibility associated with MAM pre-treatment (Gastambide et al. 2012; Gastambide et al. 2013). Using positron emission tomography and resting-state fMRI, large-scale changes in brain connectivity have been observed (Niesters et al. 2012) and detailed comparison with the connectivity patterns associated with the symptoms of psychosis seen by Xia et al. (2018) would be very informative.

A possible obstacle for translation is failing to understand species differences. Complications in drug discovery imposed by occasional species differences (e.g. in 5-HT receptor subtypes) must be acknowledged, but identifying the relevant targets and proof of principle will still depend on effective animal models. For example, a drug that inhibits ketamineinduced glutamate release in frontal cortex could predict the efficacy of a different target that serves the same function in humans, as exemplified by mGlu2/3 receptor agonists and 5HT7 receptor antagonists.

\section{Principle 4: identify molecular targets via genomic analysis and patient-derived pluripotent stem cells}

Whilst the genomic revolution promised great hope for rational target identification for novel anti-schizophrenic drugs, it is clear that schizophrenia is a disorder contingent on the interplay of a large number of genes, each with relatively small effect size. This has made difficult the development of useful genetic mouse models, quite apart from the question of functional homology. For example, unlike the stuttering gene (discussed above), engineering CNVs into mice does not always recapitulate the full spectrum of cognitive deficits of the disorder. In three engineered CNV mouse strains (15q13, $1 \mathrm{q} 21$ and 22q11), animals were found to have but subtle impairments in attention, impulsivity and vigilance (Kellendonk et al. 2009). Perhaps a second "hit" is required to precipitate a more profound behavioural phenotype, as seen with the precipitation of psychosis in individuals deemed at risk by administration of the partial inverse benzodiazepine receptor agonist iomazenil (Ahn et al. 2011). A further example is the Disrupted In Schizophrenia gene (DISC-1), a promising susceptibility factor that, when engineered into mice (Porteous et al. 2011), reduces parvalbumin in neurons in the cortex, induces enlarged lateral ventricles and hyperactivity changes in sensorimotor gating, and an anhedonia/depression-like deficit (Hikida et al. 2007). However, it was perhaps a forlorn hope that genetic studies would identify a single gene as the cause of schizophrenia.

While such examples show parallelism, though incomplete, of genetic translation between mice and human, it has not been always successful. As a note of caution, the identification of the gene associated with congenital insensitivity to pain led many to believe that the NaV1.7 ion channel gene responsible was the perfect target for a novel non-opioid analgesic. Selective inhibitors of $\mathrm{NaV} 1.7$ were duly sought and found, but they failed to show analgesic properties. More detailed investigation revealed that the gene deletion led to pleiotropic upregulation of the pro-enkephalin gene, penk (Minett et al. 2015). That is, the deletion of the one gene caused increased expression of another. Pain sensitivity in mice and human subjects can be restored by treatment with the opioid receptor antagonist naloxone (Kleber 2007), but is this pleiotropic response telling us something about endorphinergic physiology that could potentially lead us to a perfect opioid analgesic? Why, for example, is it possible to block the analgesic response to penk up-regulation without precipitating withdrawal symptoms and why do subjects with the gene deletion show no signs of tolerance or craving after treatment with naloxone? This is an instance where the body appears able to harness the positive therapeutic aspects of enkephalin, but none of the negatives.

Genetic evidence from rodents is not, therefore, always a reliable means of identifying drug targets in man, and despite the increasing use of gene editing techniques in larger animal species, the use of human material is always more attractive. The isolation and culture of patient-derived pluripotent stem cells (iPSCs) into functional neurons essentially provides the makings of a diseased brain in a test tube (Bellin et al. 2012), the neurotransmission and electrophysiology of which can be thoroughly investigated and compared with control preparations with no disease. As an example, individual studies have noted the frequent dysregulation of glial selective genes, both astrocytic and oligo-dendrocytic, in schizophrenia (Windrem et al. 2017). This has in turn led investigators to highlight the marked differences between humans and rodents in glial gene expression in contrast to the relatively conserved nature of neuronal gene expression across mammals that has suggested a correlative association of human glial evolution with the 
phylogenetic appearance of schizophrenia (Windrem et al. 2017). It is important to remember that there are likely to be genomic influences on the target expression and mechanism of action that could potentially make or break target validation. Patients with schizophrenia are characterised by a relative paucity of white matter and hypomyelination, with deficiencies in oligo-dendro-glial density and myelin structure being noted in imaging studies (Windrem et al. 2017). In order to create animal models of glial dysfunction, Han et al. (2013) engineered a model of human glial chimeric mouse brains. Patient-specific and control iPSCs were cultured and transplanted neonatally either into immunodeficient myelin wild type mice or immune-deficient hypomyelinated shiverer mice. In the human glial chimeric mice and their progeny, the majority of resident glia are replaced by human glia allowing human glial physiology. Some of the limitations of using patient derived stem cells are discussed by (Brennand et al. 2014), gene expression and effects on neurophysiological function and behaviour to be assessed in vivo. The glial chimeric mice were analysed for astrocytic and oligo-dendrocytic differentiation according to their schizophrenia derivatisation. The chimeric mice derived from patient iPSCs developed abnormal astrocytic morphology, had disturbed sleep patterns, decreased social interactions and increased anxiety, and reduced pre-pulse inhibition of the startle response. The transplant model represents an exciting example of the use of patient derived iPSCs as a tool to understand the neurobiology of schizophrenia.

We add a caution here since as pointed out by Brennand et al. (2014), iPSCs are useful for studying genetic risk mechanisms but not necessarily disease mechanisms, in part because of the immaturity of the iPSC-derived cells. As with any transgenic engineering approach it is always going to be difficult to know the time in their development cycle that recapitulates the point of optimum developmental adaptation and when to start investigation. In the glial dysfunction model described above we may be seeing the result of developmental adaptations to the genetic abnormalities rather than the immediate consequences of the original abnormalities. However, a transplant model in which the transplanted glia proliferate in situ, removes any concerns about the state of maturity of the transplanted cells.

In a phase 2 human trial of the mGlu2/3R agonist LY2140023, initial clinical results were disappointing. However, in a pharmacogenomic analysis of the data, it was discovered that 23 single nucleotide polymorphisms (SNPs) were associated with a change in positive and negative syndrome scale total score in response to 28-day treatment. There was a 30 point PANSS total reduction in the most responsive genotype group, the 5- $\mathrm{HT}_{2 \mathrm{~A}}$ receptor SNP rs7330461 (Liu et al. 2012), which was greater than the mean reduction of 22 points seen with clozapine (Siskind et al. 2017). In the study with LY2140023, sixteen of the SNPs were located in the gene coding for the 5- $\mathrm{HT}_{2 \mathrm{~A}}$ receptor (Liu et al. 2012). These results suggest that LY2140023 and other mGlu2/3 receptor agonists might be therapeutically effective in a subset of schizophrenic patients and point to the potential value, in general, of genotyping patients for treatment stratification. Indeed, the effect of LY2140023 on ketamine-induced changes in coherence in the rat begs the question whether an equivalent effect is seen in human, and therefore whether this has any functional consequence. While this is currently unknown, the data have been captured and could be analysed, and might indicate whether mGluR2/3 agonists are more clozapine-like in their effect.

Inter-regional coherence is an additional translational measure that can be readily obtained clinically and preclinically. Many psychiatric diseases are associated with changes in functional connectivity, and sparse canonical correlational analysis suggests circuit level abnormalities that cross diagnoses and reveal correlated patterns of functional connectivity and psychiatric symptoms (Xia et al. 2018). These studies inform us that not only do we need to measure global connectivity changes after administration of ketamine and LY2140023, but also the subjects should be selected to carry the $5-\mathrm{HT}_{2 \mathrm{~A}}$ polymorphism.

We are aware that genetic models have limited direct applicability to polygenic disorders. However, they may capture some part of the syndrome or even (remarkably) a "dilute" version of the syndrome as a whole (Robbins and Moore 2008; Arguello et al. 2010). Furthermore, they can be helpful in providing avenues for further investigation. For example, when a specific genetic change is identified, the distribution of the gene product in brain will give clues as to its function as will the nature of the behavioural and/or clinical phenotype. This will help identify the domain of interest which will focus the subsequent investigations. Detailed functional investigations in vitro and in vivo with transgenic animals will further direct the behavioural phenotyping and help identify the molecular target of interest i.e a mechanism by which the genetic defect can be overcome.

\section{Principle 5: embrace holistic neuroscience-a partnership with psychoneuroimmunology}

In humans, inflammation has been reported to play an instrumental role in the association between adverse social conditions and poor health outcome (Moieni et al. 2015). Using a social stress model in mice, Hodes et al. (2014) found preexisting individual differences in the sensitivity of the peripheral immune system that predict and promote vulnerability to social stress. The value of psychoimmunological signals was further strengthened by the demonstration of individual inflammatory status and its relationship to stress-induced mental health pathologies (Hodes et al. 2014). Lonely or socially 
disconnected individuals show greater inflammatory responses, including up-regulation of pro-inflammatory gene expression, and people who are sensitive to cues of social disconnection exhibit greater inflammation in response to psychological stress. Moieni et al. (2015) examined the impact of sensitivity to social disconnection (a composite score composed of loneliness, anxious attachment, fear of negative evaluation, and rejection sensitivity) on pro-inflammatory cytokines and gene expression in response to endotoxin (an inflammatory challenge) vs. placebo in a sample of 115 healthy participants (Moieni et al. 2015). Those more sensitive to social disconnection showed increased pro-inflammatory responses (i.e. increased levels of tumour necrosis factor TNF alpha and interleukin-6 (IL6)) to endotoxin, as well as upregulation of multiple genes related to inflammation. The value of psycho-immunologic signals was further strengthened by the demonstration of individual inflammatory status and its relationship to stress-induced mental health pathologies (Hodes et al. 2014). Furthermore, bioinformatics analyses revealed that those in the endotoxin group who were more sensitive to social disconnection exhibited a conserved transcriptional response to adversity (CTRA) regulatory profile, involving up-regulation of beta-adrenergic and proinflammatory transcription control pathways and downregulation of antiviral transcription factors in response to endotoxin (Cole 2019). Such findings encourage a crossdisciplinary approach that extends the armoury of drugs available to treat mental illness.

Translational examples of neuroimmunological treatments with desirable clinical outcomes include: (i) the IL6 human monoclonal antibody Sirukumab, originally developed as a treatment for rheumatoid arthritis(Pelechas et al. 2017), now also being considered as a treatment for major depressive disorder (Zhou et al. 2017), and (ii) the nonselective phosphodiesterase inhibitor pentoxifylline, an inhibitor of IL6 and TNF alpha synthesis, as a novel adjunct to antidepressant treatment in major depression (El-Haggar et al. 2018).

\section{Principle 6: use translational measures of neuronal activation}

For the mapping of the circuitry underlying psychiatric disorders, functional magnetic resonance imaging (fMRI) of blood oxygen level dependent (BOLD) signals have proved invaluable, especially when subjects simultaneously engage in cognitive tasks whilst inside the scanner. In animals, direct use of this approach for translational biomarkers is not practical since fMRI can only be carried out whilst the animals are restrained or under anaesthesia. However, there is an alternative in oxygen amperometry, which allows the determination of tissue oxygen concentration ( $\mathrm{Li}$ et al. 2016a), and can be carried out in freely moving animals whilst engaging in responding to a task in an operant chamber. A carbon paste electrode is surgically implanted in a specific brain region selected according to human imaging investigations. As with the human BOLD response, the rat BOLD and oxygen response signals increase when they breathe oxygen and decrease when they are given nitrogen (Lowry et al. 2010). If trained to press a lever in the presence of an auditory tone signalling reward delivery, oxygen rises in the nucleus accumbens (Francois et al. 2014) with a magnitude dependent on the size of the reward just as it does with monetary rewards in humans (Knutson et al. 2000).

The development of mGlu2/3 receptor agonists illustrates the value of these techniques. These agents have been developed as potential antipsychotics because of their ability to inhibit ketamine-induced glutamate release in the rat frontal cortex (Lorrain et al. 2003). Intravenous administration of ketamine induces a large prefrontal cortical BOLD response in both human and rat, and a large increase in cortical oxygen concentration in the rat, a response that was dose-dependently antagonised by the mGlu2/3 receptor agonist, LY369268 (Li et al. 2014).

Functional connectivity between brain regions can be inferred based on patterns of correlation as subjects are scanned during a passive resting state. In such resting-state fMRI studies, temporal correlations in low-frequency BOLD signal fluctuations are readily observed and have led to the identification of several resting state networks in the brain (Fox and Greicius 2010; Fox and Raichle 2007). There is evidence that restingstate networks are impacted by a number of neuropsychiatric diseases (Fox and Greicius 2010). Ketamine enhanced the coherence of low-frequency oxygen fluctuations between the frontal cortex and ventral striatum in both rat and human studies. The atypical neuroleptic, clozapine, dose-dependently attenuated the ketamine-induced absolute signal in both regions, and also the enhanced regional coherence. On the other hand, the typical neuroleptic, haloperidol, had no effect on the absolute ketamine-induced signal and potentiated the increase in regional coherence ( $\mathrm{Li}$ et al. 2014), as has been found in human studies.

A further excellent example of a translational cognitive task, validated by common circuitry across species, is the sustained attention task (SAT). The standard task consists of the random presentation of signal and no signal trials which consist of a brief visual cue following the signal or no signal event. Two response levers are extended into the chamber prompting the animal to report the presence or absence of the signal. Following signalled trials, a press on the left lever is scored as a hit and rewarded while a press on the right lever is not. In one such study transient pulses of acetylcholine release were detected voltametrically when incongruent hits were made (i.e. pressing the correct lever when no stimulus is given) and there was a shift from non-signal to signal directed responses (Howe et al. 2013). To test whether the rodent 
findings of shift-related transient activity could be conceptually replicated in humans, a second study used BOLD fMRI and a human version of the SAT found that shifts from nonsignal to signal directed processing elicited right lateral orbitofrontal cortex activity that correlated with performance. The third part of the study measured changes in tissue oxygen in rats and found again, sequence-specific transient responses, paralleling the rodent cholinergic results and human fMRI, consistent with right prefrontal cortex activation playing an important and specific role in shifts from monitoring to cue directed response.

So far, we have made the point that there should be mechanistic commonality between animal and human testing to improve the translation of preclinical findings to clinical efficacy. But this also provides a means of early proof (and disproof) of concept in volunteer and patient studies using surrogate endpoints before embarking on lengthy and costly clinical trials, as well as helping to establish such basics as dosing level and frequency, and side effects at pharmacological exposures. With the benefit of hindsight, the knowledge that mGlu2/3 receptor agonists and $5-\mathrm{HT}_{7}$ antagonists can diminish glutamate release induced by ketamine in rat prefrontal cortex, linked with the knowledge that such release would stimulate a BOLD response in humans or oxygen response in rodents, logically leads to testing the ability of mGlu2/3 receptor and $5-\mathrm{HT}_{7}$ ligands to attenuate these latter responses in both rodents and human volunteers. The rat oxygen amperometry response would provide the cheapest and quickest decision point to commission more expensive fMRI work which would then justify the human proof of concept. Even more compelling would be to translate to humans the finding of the ability of the compounds to attenuate the cognitive disruption induced by NMDA antagonist in a translational delayed non-matching to position working memory task (Bonaventure et al. 2011). In our experience this was very difficult to achieve with $\mathrm{mGlu} 2 / 3$ receptor agonists possibly because of off-target drug-drug interactions that depressed basal operant response rates (unpublished findings). Perhaps this would be mitigated by the expression of SNPs in the 5$\mathrm{HT}_{2 \mathrm{~A}}$ receptor that confer the large decrease in PANSS score seen in schizophrenics.

While the previous paragraphs have focussed on imaging as a translational technique, we also highlight the potential use of monitoring the expression of brain derived neurotrophic factor (BDNF) as a biomarker of antidepressant action for both rodents and man. The significant delay that occurs before benefit is seen with many antidepressant compounds strongly implicates downstream effects being crucially important for therapeutic benefit to occur and there is good evidence that BDNF-induced neuroplasticity is the final common pathway for antidepressant action (Stone et al. 2008). New neurons are produced throughout life in two discrete locations, the subventricular zone of the lateral ventricle and the subgranular zone of the dentate gyrus, and this occurs in humans with a range of antidepressant treatments (Anacker et al. 2011). A wide range of antidepressant treatments increase blood (serum or plasma) BDNF (Brunoni et al. 2014) whose increase is correlated with the magnitude of the antidepressant effect. The list of treatments has been more recently extended to include ketamine (Haile et al. 2014), vagal stimulation (approved for treatment resistant depression) (Lang et al. 2006), and allopregnalone (Shirayama et al. 2020). However a more recent study has failed to replicate the finding that ketamine increases blood BDNF (Medeiros et al. 2021) and more work will be needed to settle this point. Electroconvulsive therapy is also effective for treatmentresistant depression (Brunoni et al. 2014) and increases BDNF levels in blood (Bocchio-Chiavetto et al. 2006).

In rodents, antidepressants including ketamine and the atypical antidepressant tianeptine increase brain BDNF (Reagan et al. 2007; Campodoni et al. 2019), as does psilocybin (now approved for the investigation of the treatment of depression (Kargbo 2020)), and another psychedelic, LSD (Vollenweider and Kometer 2010). Exogenous delivery of BDNF promotes the function and sprouting of 5-HT containing neurons in the brains of adult rats (Siuciak et al. 1996) and animals receiving an infusion of BDNF show behaviours associated with antidepressants in learned helplessness paradigms (Altar 1999). BDNF therefore has many of the hallmarks of a useful translational biomarker for antidepressant development. Furthermore, this property of antidepressants can be monitored even in cultured neurons (Lepack et al. 2016) opening the door to high throughput screening of compounds.

Clearly there are biomarkers available that not only provide valid translational measures of pharmacodynamic action but also indicate the functional domain to which clinical trials should engage.

\section{Principle 7: validate the reproducibility of findings by independent collaboration}

Lack of reproducibility plagues biological research in general as well as in pre-clinical neuroscience (Mrazek et al. 2014). As an example of how collaboration can be used to overcome this problem, we highlight a project from the Innovative Medicines Initiative-NEWMEDS.

The NEWMEDS project (Novel Methods leading to New Medications in Depression and Schizophrenia (Stensbol and Kapur 2015, Artigas et al. 2017)) was a European Union funded, 25 million euro public/private partnership, launched by the Innovative Medicines Initiative (IMI), for academic and industrial researchers to work together in collaboration to design, review, modify and validate behavioural assays of cognition and animal models of schizophrenia disease symptoms 
(Stensbol and Kapur 2015; Plichta et al. 2012) including testretest reliability of functional imaging paradigms (Plichta et al. 2012). The project was strictly pre-clinical and all information was shared by the dozen or so industrial participants thus creating an ideal platform for inter-laboratory verification of findings.

For one company, Eli Lilly, this initiative demonstrated how independent laboratories across international borders can effectively work together to solve common problems. The company provided funding for 20 post-docs for 2-year appointments, each of whom was assigned a Lilly Neuroscience supervisor and a high-profile academic supervisor who was a leading expert in psychopharmacology, behavioural neuroscience or electrophysiology. Collectively this initiative formed the Lilly Centre for Cognitive Neuroscience. Lilly was fortunate to be geographically positioned such that $80 \%$ of the UK's neuroscience output was carried out within a 120-mi radius of the Lilly laboratories. Thus, face-to-face communication was possible on a regular basis. The postdoctoral researchers benefitted from having direct access to leading academics, their laboratories and expertise, while the IMI funding provided the resources for independent laboratories to verify methodologies and results. This was done not just by the adoption of cross-laboratory discussion and planning, but by engaging the independent groups from other collaborating companies in NEWMEDS carrying out the same experiments. Where doubt lingers, either in scientists or managers, it has been proposed that authors should sign a statement confirming that that their key findings have been replicated at least by themselves or preferably by independent collaborators (Tricklebank and Ajram 2017).

One example of the power of this approach was in the testing of the disruptive actions of a range of psychoactive compounds to impair the performance of a touchscreen based visual discrimination learning task in rats. Academic and pharma labs agreed together the experimental design, equipment, source and strain of rats to use, and the drugs, doses and pre-treatment times, and one company agreed to analyse drug concentrations achieved in brain and blood (Mohler et al. 2015). Results were qualitatively similar across all laboratories, the greatest differences reflecting strain differences in the brain concentrations of drugs achieved (Mohler et al. 2015). It was commented that since Lister Hooded rats are primarily used in European laboratories while the Long Evans strain is mainly used by North American groups, some difficulty in replicating experiments across continents might be expected. This observation reinforces the need for individual labs to fully explore dose/response relationships and not rely on published literature for dose selection.

In a second example, one pharma laboratory and one academic group together investigated the effects of the $5-\mathrm{HT}_{2 \mathrm{C}}$ receptor antagonist SB242084 (Alsio et al. 2015) in a reversal learning task using newly available touchscreen based operant equipment to approximate the human touchscreen testing of patients, i.e. with the CANTAB battery (Barnett et al. 2016). Both groups found qualitatively and quantitatively similar findings of improved reversal learning following local intracerebral infusions into the lateral OFC.

Another excellent example has been provided by the availability of 22q11.2 chromosomal microdeletion mouse models of the neurocognitive deficits found in human populations, relevant to schizophrenia and attention deficit hyperactivity disorder (ADHD). Given the sensitivity of the attentional deficits to attenuation by amphetamine in ADHD, NEWMEDS collaborations enabled a full neurobiological and behavioural analysis to be made, including the demonstration of a desynchronization of prefrontal-hippocampal oscillations, specific deficits in attentional function and their pharmacological remediation (Nilsson et al. 2018).

These examples give some grounds for optimism. There is a need for preclinical scientists to work collaboratively in a pre-competitive manner, engaging the necessary resources to execute the studies successfully, with optimum sample sizes and the requisite inter-disciplinary analysis (e.g. functional imaging, neurochemical, histological and electrophysiological) for translational validity. This strategy also enables the comparison of different candidate models to determine their common and distinctive features.

There was an attempt by Lilly to build on the success of NEWMEDS with a new proposal which was considered but unfortunately not ultimately supported by the IMI. Clearly though, this kind of interlaboratory collaboration is essential to improve the quality of preclinical research and the onus is on funders to recognise its importance through providing the necessary additional resources and perhaps for journals to become more insistent on replication of key discoveries.

\section{Principle 8: learn and reflect}

Targets that have clearly failed are also important because they bolster the belief that preclinical psychopharmacology has low predictive validity. Thus, it is very important to continue to investigate and understand what went wrong; not to apportion blame, but to reveal the real pros and cons of the target and ultimately overcome any undesirable properties that were responsible for the clinical failure (Grabb et al. 2016). Furthermore, failure of a target for one indication does not exclude the possibility of success for another and in this section we give examples of opportunities for drug repurposing.

Inhibitors of phosphodiesterase 10 (PDE10) have a preclinical profile consistent with possessing functional dopamine $\mathrm{D}_{2}$ receptor antagonism (Grauer et al. 2009) in the absence of any significant affinity for that receptor, and yet in clinical trials no beneficial antipsychotic action has been detected. Many laboratories working on this target have agreed that like all proven 
antipsychotics, all examples of PDE10 inhibitors inhibit conditioned active avoidance responses in rodents ( $\mathrm{Li}$ et al. 2016b). Fortunately, a clinically equivalent response suitable for use in a MRI scanner has now been designed (Gillan et al. 2015) so this response could now be measured clinically, although we do not know whether the behaviour is deficient in schizophrenia. There is thus a reason to follow up and test PDE10 inhibitors in the human equivalent of the CAR to (a) establish its response to known antipsychotics and (b) verify or not its sensitivity to PDE10 inhibition. Ideally, the human conditioned avoidance task will be found sensitive to disruption by neuroleptic agents and allow fMRI to identify the relevant circuitry at which PDE10 inhibitors act, which then could guide rodent studies to confirm whether the human and rodent tasks are utilising homologous circuitries. Similarly, a detailed comparison of regional connectivity changes induced by therapeutic doses of a known antipsychotic compared to the response to a PDE10 inhibitor might indicate the functional differences between these mechanisms, as was noted for the $\mathrm{mGlu} 2 / 3$ receptor agonists.

The above example also highlights the danger of adopting a single traditional behavioural assay to indicate the clinical target without consideration of the principles outlined here. It has been hypothesised that in addition to dopamine $\mathrm{D}_{2}$ receptor blockade the superior efficacy of clozapine is related to its high affinity for $5-\mathrm{HT}_{2}$ receptors. This prompted the search for selective $5-\mathrm{HT}_{2}$ receptor antagonists which were duly found and thought to be antipsychotics without risk of inducing extrapyramidal side effects. One compound M100907 indeed showed a preclinical profile (Sorensen et al. 1993) consistent with what was known about atypical neuroleptics at the time. However, this did not translate into clinical efficacy. Nevertheless, another $5-\mathrm{HT}_{2}$ receptor antagonist, primavanserin, has shown efficacy in the treatment of psychosis associated with Parkinson's disease (Tampi et al. 2019) and was approved by the FDA for the treatment of hallucination and delusions associated this condition. This could be seen as an illustration of the benefits of adopting an RDoC approach. Clearly the mechanism underlying the generation of psychosis in Parkinson's might be different from that of schizophrenia, although clozapine is effective in Parkinson's patients (Combs and Cox 2017). 5- $\mathrm{HT}_{2 \mathrm{~A}}$ receptor agonists are a well characterised class of psychotomimetic agents and linking these findings with the antipsychotic effects of mGlu2/3 receptor agonists could provide fertile ground for understanding the lack of clinical efficacy of selective 5$\mathrm{HT}_{2 \mathrm{~A}}$ receptor antagonists in schizophrenia.

\section{Promising progress with novel compounds}

Some compounds have recently been produced using a strategy that is not entirely dissimilar to the one we have described above, and we highlight in this section some recently approved or experimental drugs for major psychiatric conditions whose properties suggest that they might have broader utility than that first indicated. These drugs exemplify our proposition that application of the principles described in this paper might positively influence clinical outcome and therapeutic potential.

\section{Schizophrenia}

The 5- $\mathrm{HT}_{7}$ receptor antagonist, SB6561014, blocks NMDA antagonist-induced glutamate release in the prefrontal cortex (Bonaventure et al. 2011) This drug also impressively reverses the effects of the non-competitive NMDA receptor antagonist, MK-801, to impair working memory, using a translationallyrelevant delayed non-match-to-position task (Bonaventure et al. 2011). As 5- $\mathrm{HT}_{2 \mathrm{~A}}$ receptor single nucleotide polymorphisms have been shown to amplify the therapeutic response to the $\mathrm{mGlu} 2 / 3$ receptor agonists described above (Liu et al. 2012), it would be of value to see if this also holds for any therapeutic response to $5-\mathrm{HT}_{7}$ receptor antagonists, as they might for other similar compounds, e.g. amisulpride (Abbas et al. 2009) and LY215840 (Cushing et al. 1996) that possess appreciable affinity for $5-\mathrm{HT}_{7}$ receptors.

The atypical neuroleptic lumateperone (Caplyta) has been recently approved for the treatment of schizophrenia and is in development for bipolar depression (Kumar et al. 2018). This drug acts as a partial agonist at presynaptic $\mathrm{D}_{2}$ dopamine receptors and an antagonist at post-synaptic $\mathrm{D}_{2}$ receptors. It modulates serotonin through its affinity for the serotonin transporter and is a $5-\mathrm{HT}_{2 \mathrm{~A}}$ receptor antagonist. Associated with its $D_{1}$ receptor activation is increased activity at NMDA receptors with enhanced GluR2B receptor phosphorylation (Kumar et al. 2018). Given its unusual receptor binding profile, it is being promoted as a serotonin, dopamine and glutamate modulator with efficacy and safety in patients with acute exacerbation of psychosis.

Brexpiprazole was approved in 2015, a molecule which has partial agonist activity at dopamine $\mathrm{D}_{2}$ receptors and antagonist activity at $\mathrm{D}_{3}, 5-\mathrm{HT}_{2 \mathrm{~A}}, 5-\mathrm{HT}_{2 \mathrm{~B}}$ and $5-\mathrm{HT}_{7}$ receptors (Das et al. 2016). Like clozapine, it has agonist activity at 5$\mathrm{HT}_{1 \mathrm{~A}}$ receptors and an antagonist action at alpha $\mathrm{A}_{\mathrm{A}}$, alpha $\mathrm{C}$, alpha $_{1 \mathrm{~B}}$, and alpha $\mathrm{D}_{\mathrm{D}}$-adrenergic receptors. Of particular significance is the interaction with $5-\mathrm{HT}_{7}$ and $5-\mathrm{HT}_{1 \mathrm{~A}}$ receptors which like SEP363856 (see below) might owe some of its anti-schizophrenic properties to stimulation of oxytocin release (Souza et al. 2010)through agonist action at $5 \mathrm{HT}_{1 \mathrm{~A}}$ receptors (Bagby and Kalogeras, 1993). Efficacy might therefore also be linked like clozapine to the presence of oxytocin receptor single nucleotide polymorphisms as well as those of the 5- $\mathrm{HT}_{2 \mathrm{~A}}$ receptor (Liu et al. 2012).

While we espouse the predictive validity approach to drug discovery, we cannot ignore any approach that contributes to 
advancing psychiatric medicine. The compound SEP363856 was found via a novel mouse behaviour phenotyping battery. Thousands of features were collected and a proprietary bioinformatic algorithm was employed to select subtle phenotypic differences associated with a disease model or drug effect. Despite being devoid of any significant affinity for dopamine $\mathrm{D}_{2}$ receptors the compound nevertheless demonstrated broad efficacy in rodent schizophrenia models, including phencyclidine-induced hyperactivity, pre-pulse inhibition and PCP-induced deficits in social interaction (Dedic et al. 2019). Given its favourable toxicological profile and pharmacokinetic properties, SEP363856 was progressed to a 4-week randomised placebo-controlled trial in hospitalised schizophrenics. The mean reduction from the baseline PANSS at week 4 was significantly greater for SEP363856 vs placebo (17.2 vs 9.7, $p=0.001$, effect size 0.37 ), in the absence of changes in prolactin secretion or major side effects (Koblan et al. 2020), and the drug is currently in phase 3 trials for schizophrenia. The only identified pharmacological properties of the compound include affinity for the $5-\mathrm{HT}_{1 \mathrm{~A}}$ receptor and trace amine receptor 1 . The behavioural phenotype can be antagonised by the $5-\mathrm{HT}_{1 \mathrm{~A}}$ receptor antagonist WAY100635 but there is no evidence that the $5-\mathrm{HT}_{1 \mathrm{~A}}$ partial agonist buspirone has significant impact on schizophrenic symptoms apart from a possible impact on negative symptoms (Sheikhmoonesi et al. 2015). The mechanism of action of SEP363856 therefore remains uncertain. Again it is possible the effects are mediated via serotonergic stimulation of oxytocin release (Bagdy and Kalogeras 1993), while (Kokkinou et al. 2020), using sub-chronic ketamine administration to replicate schizophrenia-like alterations in dopamine metabolism, found that SEP363856 was able to antagonise these changes.

\section{Depression}

The ketamine story has already been discussed. Associated with these findings, the metabolite of ketamine, Snorketamine, has an agonist effect at AMPA receptors (Zanos et al. 2018). The sensitivity of ketamine's antidepressant action to attenuation by an AMPA receptor antagonist such as perampanel would be a very informative experimental medicine project. Ketamine is notable for its ability to reduce suicidal feelings (Phillips et al. 2020). Postmortem studies following suicide have revealed a high concentration of the potentially excitotoxic NMDA receptor agonist, quinolinic acid, in plasma, CSF and brain tissue (Brundin et al. 2016; Steiner et al. 2011), suggesting that ketamine may be exerting its anti-suicidal effects via blockade of the effects of quinolinic acid. Quinolinic acid is a metabolite of the tryptophan oxidase pathway, produced by exposure to stress (Brundin et al. 2016) and the tryptophan/kynurenine pathway plays a pivotal role in the onset of depression (Sakurai et al. 2020), leading to the suggestion that tryptophan oxidase inhibitors may be effective anti-depressants.

There is also the potential of utilising drugs affecting neuropeptide systems in psychiatric disorders. Numerous experimental medicine studies have indicated the ability of oxytocin (Guastella et al. 2010) to exert beneficial effects in disorders with prominent deficits in social cognition (autism spectrum disorders, schizophrenia (Oya et al. 2016) and depression (Domes et al. 2016)). The compound is limited unfortunately by its poor brain penetration. A number of approaches could overcome this problem by stimulating endogenous oxytocin release or modulating oxytocin activity. One such example is the family of melanocytestimulating hormones (MSH) consisting of peptides including $\alpha$-MSH, $\beta$-MSH, and $\gamma$-MSH that are produced in the cells of the pars intermedia of the anterior lobe of the pituitary gland. Preclinical studies have indicated important roles in the regulation of food intake and metabolism, however, there is also evidence of involvement in social cognition, e.g. social bonding in animals, via interactions with oxytocin (Kirsch et al. 2005). A comprehensive investigation of the psychopharmacological properties of melanocortin 4 receptor agonists has conclusively demonstrated the ability of the compounds melanotan I, melanotan II and PF446687 to enhance partner preference formation in the monogamous prairie vole but not in the nonmonogamous meadow vole, effects that were blocked by central administration of an oxytocin receptor antagonist. Melanotan II also activated hypothalamic oxytocinergic neurons and potentiated oxytocin release (Modi et al. 2015). Sadly lacking in these studies for definitive evidence of the role of oxytocin has been the lack of availability of the brain penetrant oxytocin receptor antagonist L-368,899 for clinical mechanistic investigation (Boccia et al. 2007).

Vagal stimulation has also recently been proved an effective anti-depressant treatment in treatment-resistant cases (Ondicova et al. 2010). Its mechanism of action is currently unknown although in rodents it can stimulate the release of neuropeptides such as oxytocin (Stock and Uvnas-Moberg 1988) and BDNF, and has anti-inflammatory properties, possibly also mediated by oxytocin (Clodi et al. 2008). This finding might also be considered to support principle 5. The glycine site NMDA partial agonist Glyx 13 (rapastinel) has also demonstrated antidepressant activity preclinically and upregulates BDNF (Kato and Duman 2020), and was recently approved for trials in major depressive disorder by the FDA. It is without risk of the major side effects seen with ketamine but failed to meet its clinical endpoint. The FDA has also recently approved a clinical trial of psilocybin for treatment-resistant depression (Kargbo 2020). Thus, there are now exciting new ideas for treatment-resistant depression, although their mechanisms are not yet well established. 


\section{Indication discovery and drug repurposing}

Some opportunities have been missed for detecting alternative applications of molecules with well-specified modes of action that have not, however, met their primary targets (Kleber 2007). There are many examples of CNS compounds that have been discarded because they failed in clinical trials for a particular indication, when in fact they may have been more productively tried in alternative disorders. To increase the chances of identifying existing drugs that can be beneficial for psychiatric disorders, a systematic search has been recommended (Nutt 2014).The RDoC approach should facilitate this process of "indication discovery" by effectively screening the functional properties of compounds across the domains of psychopathology.

Some relevant examples of drug repurposing are provided in the case of alcohol use disorders. A high proportion of violent acts are committed under the influence of alcohol. Aggressive behaviour can also be primed in the mouse by exposure to alcohol (De Almeida et al. 2001). In findings that are consistent with our knowledge of the relationship between serotonin and aggression (Pihl and Lemarquand 1998), this impact of alcohol can be ameliorated by treatment with the $5-\mathrm{HT}_{1 \mathrm{~B} / 1 \mathrm{D}}$ receptor agonist zolmitriptan, an approved anti-migraine drug. However, these findings have seemingly been overlooked despite the consistency of rodent and human data (Gowin et al. 2010). Similarly overlooked has been the positive outcome of a metaanalysis into the ability of LSD to treat alcoholism in six trials involving 536 participants (Krebs and Johansen 2012). There was striking evidence of a beneficial effect $(p<0.0003)$ on alcohol misuse. Hopefully a more rational attitude and approach to the therapeutic benefits of scheduled agents like LSD will result in their therapeutic potential being realised as it might for psilocybin in treatmentresistant depression (Carhart-Harris et al. 2016).

The current opioid crisis in both the UK and the USA has resulted in many deaths, mostly due to suppression of respiration. The treatment of choice is the opioid antagonist naloxone although that usually precipitates intense withdrawal symptoms and the reinstatement of pain (Kleber 2007). Yet, it is known that opiate-induced respiratory depression can be overcome without loss of analgesia by activation of $5-\mathrm{HT}_{4}$ receptors which are expressed on the pre-Botzinger complex and do not influence opioid receptors because $5-\mathrm{HT}_{4}$ receptors are not expressed in pain processing regions (Manzke et al. 2003; Meyer et al. 2006). The compound zacopride, a 5-HT 3 receptor antagonist, also possesses significant agonist activity at $5-\mathrm{HT}_{4}$ receptors and reverses opioid-induced respiratory depression in animal studies (Meyer et al. 2006). $5-\mathrm{HT}_{1 \mathrm{~A}}$ receptor stimulation exerts similar effects, and the $5-\mathrm{HT}_{1 \mathrm{~A}}$ agonist sarizotan has orphan drug status for relieving respiratory depression in the rare disease, Rett syndrome (BioSpace
2015). Clinical studies of such agents in opiate-induced respiratory depression would seem long overdue.

\section{Ethical considerations}

The steps we propose to encourage reinvestment in psychiatric drug discovery are based largely on better scientific knowledge of underlying neuronal circuitry, improved validation of animal tests and greater attention to their reproducibility and robustness. These principles are entirely consistent with the application of the 3Rs (replacement, reduction and refinement of animal research). Principle 7, which outlines the importance of reproducibility, will need the sympathy of funders to make allowance for increased resources for the repetition of experiments, particularly if carried out in independent laboratories. However, failure to do so merely adds to the large body of poorly carried out and poorly reported work which delays scientific advance and is ethically indefensible.

Whatever the legislative backing for the 3Rs, neuroscientists should nevertheless acknowledge and accept their ethical responsibility to ensure that animals do not suffer unnecessarily and that their use contributes meaningfully to the advancement of medicine. This means that the use of any experimental procedure must be considered in the light of alternatives, both animal and non-animal, and justified through a rigorous consideration of the balance of likely benefits and realistic harms. It is not only the pharmaceutical industry where faith in preclinical psychopharmacology needs to be restored but also society in general, whose acceptance of animal research is contingent on the minimisation of harm and belief in its necessity. We are aware that the change in approach we recommend here will be unfamiliar to society, whose expectation would be that animal models recapitulate in their entirety the current definitions of mental disorder. It is therefore incumbent on us, the scientists, to exercise our public engagement responsibilities and so ensure society understands the advances in neuroscience that will ultimately result in new medicines.

\section{Summary}

We conclude by giving an example in Fig. 2 of how the eight principles might be applied in a specific example - cognitive deficits in schizophrenia.

In order to enhance target validation and make clinical "proof of concept" investigations easier, investigators should use these principles to ensure that behavioural assays used to quantify drug effects are tapping translationally relevant brain circuitry. Concomitant determination of physiological measures of neuronal activation in behaving animals not only confirms the translational validity of the tasks 
Fig. 2 Schematic diagram to illustrate how in practice the 8 principles (identified by digits), applied in the sequence identified by arrows, might enhance CNS drug discovery, in the case of a specific example, drugs to enhance cognition in schizophrenia. See legend to Fig. 1 for further description. Not all medications would necessarily require deployment of all 8 principles

\section{The 8 Principles; How they work in Practice}

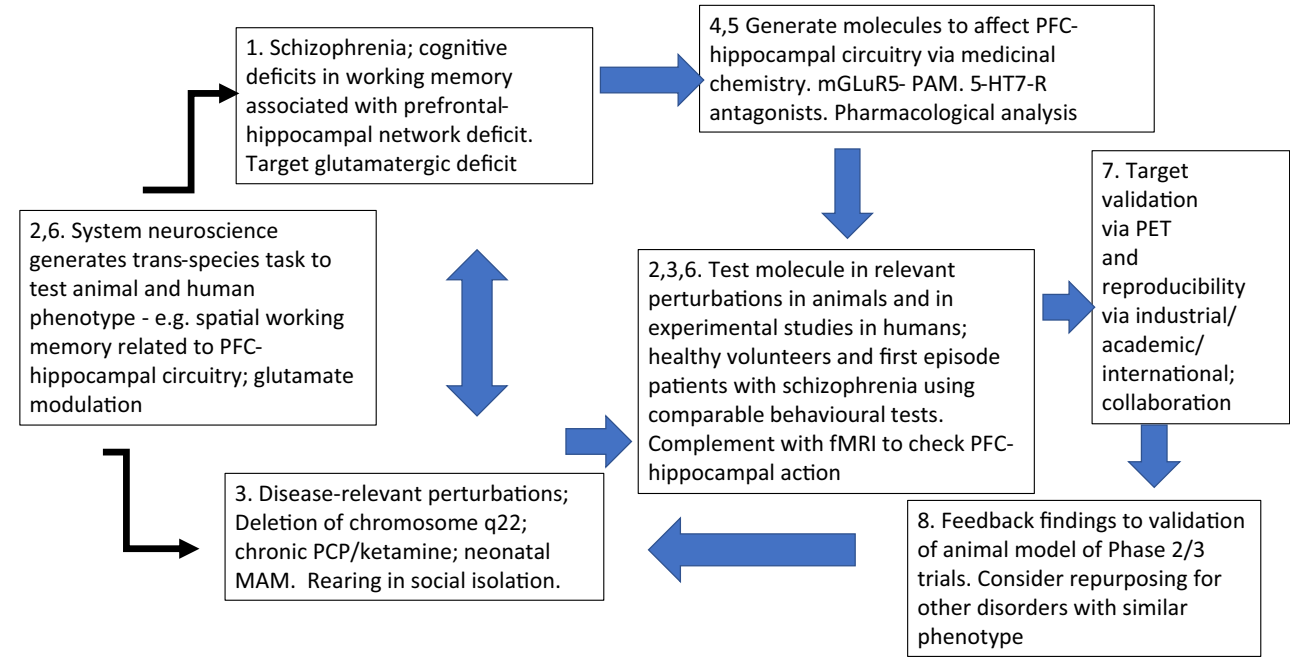

but also allows the rehearsal of clinical proof of concept studies pre-clinically when carried out in conjunction with baseline manipulations that disturb the circuitry in a disease-relevant manner to maximise the commonality between preclinical and clinical testing.

Urgent unmet clinical needs necessitate renewed investment by pharma and/or government agencies, and pharma is urged to reconsider its stance as the only viable route to provide new pharmacological agents and treatment options. The pharma industry and patient advocates are encouraged to work together to deliver on patient needs, and in the process, benefit their own organizations in a win-win scenario. Industry and other stakeholders have an opportunity to take into account the learning and reflection to find a path to successful psychiatric drug discovery and development to meet impending global mental crisis in the time of the coronavirus.

Acknowledgements MT would like to acknowledge the contributions made by my ex-colleagues at Eli Lilly and the Lilly Centre for Cognitive Neuroscience, both industrial and academic, in particular Ian Ragan, Gary Gilmour, Francois Gastambide, Jennifer Li, Sophie Dix, Janice Smith, Jennifer Francois, Adam Schwarz, Jeff Witkin, Joseph Garner, David Bannerman, John Lowry and Matt Jones; also colleagues from NEWMEDS, Tine Stensbol, Shitij Kapur, Thomas Steckler, Steve Williams, Mitul Mehta, Michael Spedding and Eileen Daly. TWR acknowledges contributions from his main NEWMEDS collaborators, TJ Bussey, J Alsio, S. Nilsson and A Mar.

Funding Work leading to this review received funding from the Innovative Medicines Initiative Joint Undertaking under grant agreement no. 115008 .

\section{Declarations}

Conflict of interest TWR discloses consultancy and royalties with Cambridge Cognition and consultancy with Greenfield Bioventures,
Takeda, Arcadia, Heptares and Cassava. He holds research grants with GlaxoSmithKline and Shionogi.

\section{References}

Abbas AI, Hedlund PB, Huang XP, Tran TB, Meltzer HY, Roth BL (2009) Amisulpride is a potent 5-HT7 antagonist: relevance for antidepressant actions in vivo. Psychopharmacology 205:119-128

Abdallah CG, De Feyter HM, Averill LA, Jiang L, Averill CL, Chowdhury GMI, Purohit P, DE Graaf RA, Esterlis I, Juchem C, Pittman BP, Krystal JH, Rothman DL, Sanacora G, Mason GF (2018) The effects of ketamine on prefrontal glutamate neurotransmission in healthy and depressed subjects. Neuropsychopharmacology 43:2154-2160

Ahn K, Gil R, Seibyl J, Sewell RA, D'souza DC (2011) Probing GABA receptor function in schizophrenia with iomazenil. Neuropsychopharmacology 36:677-683

Alsio J, Nilsson SR, Gastambide F, Wang RA, Dam SA, Mar AC, Tricklebank M, Robbins TW (2015) The role of 5-HT2C receptors in touchscreen visual reversal learning in the rat: a cross-site study. Psychopharmacology 232:4017-4031

Altar CA (1999) Neurotrophins and depression. Trends Pharmacol Sci 20:59-62

Anacker C, Zunszain PA, Cattaneo A, Carvalho LA, Garabedian MJ, Thuret S, Price J, Pariante CM (2011) Antidepressants increase human hippocampal neurogenesis by activating the glucocorticoid receptor. Mol Psychiatry 16:738-750

Anticevic A, Gancsos M, Murray JD, Repovs G, Driesen NR, Ennis DJ, Niciu MJ, Morgan PT, Surti TS, Bloch MH, Ramani R, Smith MA, Wang XJ, Krystal JH, Corlett PR (2012) NMDA receptor function in large-scale anticorrelated neural systems with implications for cognition and schizophrenia. Proc Natl Acad Sci U S A 109: $16720-16725$

Arguello PA, Markx S, Gogos JA, Karayiorgou M (2010) Development of animal models for schizophrenia. Disease Models \& Mechanisms $3: 22$

Artigas F, Schenker E, Celada P, Spedding M, Llado-Pelfort L, Jurado N, Nunez M, Santana N, Troyano-Rodriguez E, Riga MS, VAN DEN Munkhof H, Castane A, Shaban H, Jay TM, Tripathi A, Godsil BP, Sebban C, Mariani J, Faure P, Takkilah S, Hughes ZA, Siok CJ, Hajos M, Wicke K, Gass N, Weber-Fahr W, Sartorius A, Becker R, Didriksen M, Bastlund JF, Tricklebank M, Risterucci C, Meyer- 
Lindenberg A, Schwarz AJ (2017) Defining the brain circuits involved in psychiatric disorders: IMI-NEWMEDS. Nat Rev Drug Discov 16:1-2

Bagdy G, Kalogeras KT (1993) Stimulation of 5-HT1A and 5-HT2/5HT1C receptors induce oxytocin release in the male rat. Brain Res 611:330-332

Barbey AK (2018) Network Neuroscience Theory of Human Intelligence. Trends Cogn Sci 22:8-20

Bari A, Mar AC, Theobald DE, Elands SA, Oganya KC, Eagle DM, Robbins TW (2011) Prefrontal and monoaminergic contributions to stop-signal task performance in rats. J Neurosci 31:9254-9263

Barnett JH, Blackwell AD, Sahakian BJ, Robbins TW (2016) The paired associates learning (PAL) test: 30 years of CANTAB translational neuroscience from laboratory to bedside in dementia Research. Curr Top Behav Neurosci 28:449-474

Bellin M, Marchetto MC, Gage FH, Mummery CL (2012) Induced pluripotent stem cells: the new patient? Nat Rev Mol Cell Biol 13:713726

BIOSPACE (2015) Newron Pharmaceuticals Receives FDA Orphan Drug Designation For Sarizotan For The Treatment Of Rett Syndrome [Online]. https://www.biospace.com/article/releases/ newron-pharmaceuticals-receives-fda-orphan-drug-designation-forsarizotan-for-the-treatment-of-rett-syndrome-/. Accessed 20 May 2020

Birrell JM, Brown VJ (2000) Medial frontal cortex mediates perceptual attentional set shifting in the rat. J Neurosci 20:4320-4324

Bocchio-Chiavetto L, Zanardini R, Bortolomasi M, Abate M, Segala M, Giacopuzzi M, Riva MA, Marchina E, Pasqualetti P, Perez J, Gennarelli M (2006) Electroconvulsive Therapy (ECT) increases serum Brain Derived Neurotrophic Factor (BDNF) in drug resistant depressed patients. Eur Neuropsychopharmacol 16:620-624

Boccia ML, Goursaud AP, Bachevalier J, Anderson KD, Pedersen CA (2007) Peripherally administered non-peptide oxytocin antagonist, L368,899, accumulates in limbic brain areas: a new pharmacological tool for the study of social motivation in non-human primates. Horm Behav 52:344-351

Bonaventure P, Aluisio L, Shoblock J, Boggs JD, Fraser IC, Lord B, Lovenberg TW, Galici R (2011) Pharmacological blockade of serotonin 5-HT(7) receptor reverses working memory deficits in rats by normalizing cortical glutamate neurotransmission. PLoS One 6: e20210

Brady LS, Potter WZ, Gordon JA (2019) Redirecting the revolution: new developments in drug development for psychiatry. Expert Opin Drug Discovery 14:1213-1219

Brennand KJ, Landek-Salgado MA, Sawa A (2014) Modeling Heterogeneous Patients With a Clinical Diagnosis of Schizophrenia With Induced Pluripotent Stem Cells. Biol Psychiatry 75:936-944

Brundin L, Sellgren CM, Lim CK, Grit J, Palsson E, Landen M, Samuelsson M, Lundgren K, Brundin P, Fuchs D, Postolache TT, Traskman-Bendz L, Guillemin GJ, Erhardt S (2016) An enzyme in the kynurenine pathway that governs vulnerability to suicidal behavior by regulating excitotoxicity and neuroinflammation. Transl Psychiatry 6:e865

Brunoni AR, Baeken C, Machado-Vieira R, Gattaz WF, Vanderhasselt M-A (2014) BDNF blood levels after electroconvulsive therapy in patients with mood disorders: A systematic review and meta-analysis. The World Journal of Biological Psychiatry 15:411-418

Burkett JP, Andari E, Johnson ZV, Curry DC, DE Waal FB, Young LJ (2016) Oxytocin-dependent consolation behavior in rodents. Science 351:375-378

Campodoni E, Heggset EB, Rashad A, Ramirez-Rodriguez GB, Mustafa K, Syverud K, Tampieri A, Sandri M (2019) Polymeric 3D scaffolds for tissue regeneration: Evaluation of biopolymer nanocomposite reinforced with cellulose nanofibrils. Mater Sci Eng C Mater Biol Appl 94:867-878
Carhart-Harris RL, Bolstridge M, Rucker J, Day CM, Erritzoe D, Kaelen M, Bloomfield M, Rickard JA, Forbes B, Feilding A, Taylor D, Pilling S, Curran VH, Nutt DJ (2016) Psilocybin with psychological support for treatment-resistant depression: an open-label feasibility study. Lancet Psychiatry 3:619-627

Chamberlain SR, Sahakian BJ (2007) The neuropsychiatry of impulsivity. Curr Opin Psychiatry 20:255-261

Chamberlain SR, Hampshire A, Muller U, Rubia K, DEL Campo N, Craig K, Regenthal R, Suckling J, Roiser JP, Grant JE, Bullmore ET, Robbins TW, Sahakian BJ (2009) Atomoxetine modulates right inferior frontal activation during inhibitory control: a pharmacological functional magnetic resonance imaging study. Biol Psychiatry 65:550-555

Clineschmidt BV (1982) Effect of the benzodiazepine receptor antagonist Ro 15-1788 on the anticonvulsant and anticonflict actions of MK801. Eur J Pharmacol 84:119-121

Clodi M, Vila G, Geyeregger R, Riedl M, Stulnig TM, Struck J, Luger TA, Luger A (2008) Oxytocin alleviates the neuroendocrine and cytokine response to bacterial endotoxin in healthy men. Am J Physiol Endocrinol Metab 295:E686-E691

Cole SW (2019) The Conserved Transcriptional Response to Adversity. Curr Opin Behav Sci 28:31-37

Combs BL, Cox AG (2017) Update on the treatment of Parkinson's disease psychosis: role of pimavanserin. Neuropsychiatr Dis Treat 13: $737-744$

Cristea IA, Naudet F (2019) US Food and Drug Administration approval of esketamine and brexanolone. Lancet Psychiatry 6:975-977

Cushing DJ, Zgombick JM, Nelson DL, Cohen ML (1996) LY215840, a high-affinity 5-HT7 receptor ligand, blocks serotonin-induced relaxation in canine coronary artery. J Pharmacol Exp Ther 277:1560 1566

Cuthbert BN, Insel TR (2013) Toward the future of psychiatric diagnosis: the seven pillars of RDoC. BMC Med 11:126

Das S, Barnwal P, Winston AB, Mondal S, Saha I (2016) Brexpiprazole: so far so good. Ther Adv Psychopharmacol 6:39-54

De Almeida RM, Nikulina EM, Faccidomo S, Fish EW, Miczek KA (2001) Zolmitriptan-a 5-HT1B/D agonist, alcohol, and aggression in mice. Psychopharmacology 157:131-141

Deakin JF, Lees J, Mckie S, Hallak JE, Williams SR, Dursun SM (2008) Glutamate and the neural basis of the subjective effects of ketamine: a pharmaco-magnetic resonance imaging study. Arch Gen Psychiatry 65:154-164

Dedic N, Jones PG, Hopkins SC, Lew R, Shao L, Campbell JE, Spear KL, Large TH, Campbell UC, Hanania T, Leahy E, Koblan KS (2019) SEP-363856, a novel psychotropic agent with a unique, non-D2 receptor mechanism of action. J Pharmacol Exp Ther 371: $1-14$

Dias R, Robbins TW, Roberts AC (1996) Dissociation in prefrontal cortex of affective and attentional shifts. Nature 380:69-72

Domes G, Normann C, Heinrichs M (2016) The effect of oxytocin on attention to angry and happy faces in chronic depression. BMC Psychiatry $16: 92$

Dwyer DM (2012) EPS Prize Lecture. Licking and liking: the assessment of hedonic responses in rodents. Q J Exp Psychol (Hove) 65:371394

El-Haggar SM, Eissa MA, Mostafa TM, El-Attar KS, Abdallah MS (2018) The phosphodiesterase inhibitor pentoxifylline as a novel adjunct to antidepressants in major depressive disorder patients: a proof-of-concept, randomized, double-blind, placebo-controlled trial. Psychother Psychosom 87:331-339

Fox MD, Greicius M (2010) Clinical applications of resting state functional connectivity. Front Syst Neurosci 4:19

Fox MD, Raichle ME (2007) Spontaneous fluctuations in brain activity observed with functional magnetic resonance imaging. Nat Rev Neurosci 8:700-711 
Francois J, Huxter J, Conway MW, Lowry JP, Tricklebank MD, Gilmour G (2014) Differential contributions of infralimbic prefrontal cortex and nucleus accumbens during reward-based learning and extinction. J Neurosci 34:596-607

Fujita-Jimbo E, Momoi T (2014) Specific expression of FOXP2 in cerebellum improves ultrasonic vocalization in heterozygous but not in homozygous Foxp2 (R552H) knock-in pups. Neurosci Lett 566: $162-166$

Gastambide F, Cotel MC, Gilmour G, O'neill MJ, Robbins TW, Tricklebank MD (2012) Selective remediation of reversal learning deficits in the neurodevelopmental MAM model of schizophrenia by a novel mGlu5 positive allosteric modulator. Neuropsychopharmacology 37:1057-1066

Gastambide F, Gilmour G, Robbins TW, Tricklebank MD (2013) The mGlu(5) positive allosteric modulator LSN2463359 differentially modulates motor, instrumental and cognitive effects of NMDA receptor antagonists in the rat. Neuropharmacology 64:240-247

Gastambide F, Taylor AM, Palmer C, Svard H, Karjalainen M, Janhunen SK, Tricklebank M, Bannerman DM (2015) Alterations in spatial memory and anxiety in the MAM E17 rat model of hippocampal pathology in schizophrenia. Psychopharmacology 232:4099-4112

Germine L, Dillon DG, Baker J, Passell E, Vogel S, Scheuer L, Mirin N, Rutter L, Pizzagalli D (2019) S59. Digital Cognitive Assessment: Results From the Testmybrain NIMH RDoC Field Test Battery Report. Biol Psychiatry 85:S319

Gillan CM, Apergis-Schoute AM, Morein-Zamir S, Urcelay GP, Sule A, Fineberg NA, Sahakian BJ, Robbins TW (2015) Functional neuroimaging of avoidance habits in obsessive-compulsive disorder. Am J Psychiatry 172:284-293

Gowin JL, Swann AC, Moeller FG, Lane SD (2010) Zolmitriptan and human aggression: interaction with alcohol. Psychopharmacology 210:521-531

Grabb MC, Cross AJ, Potter WZ, Mccracken JT (2016) Derisking psychiatric drug development: The NIMH's Fast Fail Program, a novel precompetitive model. J Clin Psychopharmacol 36:419-421

Grauer SM, Pulito VL, Navarra RL, Kelly MP, Kelley C, Graf R, Langen B, Logue S, Brennan J, Jiang L, Charych E, Egerland U, Liu F, Marquis KL, Malamas M, Hage T, Comery TA, Brandon NJ (2009) Phosphodiesterase 10A inhibitor activity in preclinical models of the positive, cognitive, and negative symptoms of schizophrenia. J Pharmacol Exp Ther 331:574-590

Guastella AJ, Einfeld SL, Gray KM, Rinehart NJ, Tonge BJ, Lambert TJ, Hickie IB (2010) Intranasal oxytocin improves emotion recognition for youth with autism spectrum disorders. Biol Psychiatry 67:692694

Haile CN, Murrough JW, Iosifescu DV, Chang LC, Al Jurdi RK, Foulkes A, Iqbal S, Mahoney JJ, De La Garza R, Charney DS, Newton TF, Mathew SJ (2014) Plasma brain derived neurotrophic factor (BDNF) and response to ketamine in treatment-resistant depression. Int J Neuropsychopharmacol 17:331-336

Hammerschlag AR, DE Leeuw CA, Middeldorp CM, Polderman TJC (2020) Synaptic and brain-expressed gene sets relate to the shared genetic risk across five psychiatric disorders. Psychol Med 50:16951705

Han X, Chen M, Wang F, Windrem M, Wang S, Shanz S, Xu Q, Oberheim NA, Bekar L, Betstadt S, Silva AJ, Takano T, Goldman SA, Nedergaard M (2013) Forebrain engraftment by human glial progenitor cells enhances synaptic plasticity and learning in adult mice. Cell Stem Cell 12:342-353

Han TU, Root J, Reyes LD, Huchinson EB, Hoffmann JD, Lee WS, Barnes TD, Drayna D (2019) Human GNPTAB stuttering mutations engineered into mice cause vocalization deficits and astrocyte pathology in the corpus callosum. Proc Natl Acad Sci U S A 116: $17515-17524$
Hernandez-Lallement J, Attah AT, Soyman E, Pinhal CM, Gazzola V, Keysers C (2020) Harm to others acts as a negative reinforcer in rats. Curr Biol 30:949-961 e7

Hikida T, Jaaro-Peled H, Seshadri S, Oishi K, Hookway C, Kong S, Wu D, Xue R, Andrade M, Tankou S, Mori S, Gallagher M, Ishizuka K, Pletnikov M, Kida S, Sawa A (2007) Dominant-negative DISC1 transgenic mice display schizophrenia-associated phenotypes detected by measures translatable to humans. Proc Natl Acad Sci U S A 104:14501-14506

Hodes GE, Pfau ML, Leboeuf M, Golden SA, Christoffel DJ, Bregman D, Rebusi N, Heshmati M, Aleyasin H, Warren BL, Lebonte B, Horn S, Lapidus KA, Stelzhammer V, Wong EH, Bahn S, Krishnan V, Bolanos-Guzman CA, Murrough JW, Merad M, Russo SJ (2014) Individual differences in the peripheral immune system promote resilience versus susceptibility to social stress. Proc Natl Acad Sci U S A 111:16136-16141

Howe WM, Berry AS, Francois J, Gilmour G, Carp JM, Tricklebank M, Lustig C, Sarter M (2013) Prefrontal cholinergic mechanisms instigating shifts from monitoring for cues to cue-guided performance: converging electrochemical and fMRI evidence from rats and humans. J Neurosci 33:8742-8752

Howe WM, Tierney PL, Young DA, Oomen C, Kozak R (2015) MAM (E17) rodent developmental model of neuropsychiatric disease: disruptions in learning and dysregulation of nucleus accumbens dopamine release, but spared executive function. Psychopharmacology 232:4113-4127

Insel TR, Voon V, Nye JS, Brown VJ, Altevogt BM, Bullmore ET, Goodwin GM, Howard RJ, Kupfer DJ, Malloch G, Marston HM, Nutt DJ, Robbins TW, Stahl SM, Tricklebank MD, Williams JH, Sahakian BJ (2013) Innovative solutions to novel drug development in mental health. Neurosci Biobehav Rev 37:2438-2444

Kargbo RB (2020) Psilocybin therapeutic research: the present and future paradigm. ACS Med Chem Lett 11:399-402

Kato T, Duman RS (2020) Rapastinel, a novel glutamatergic agent with ketamine-like antidepressant actions: Convergent mechanisms. Pharmacol Biochem Behav 188:172827

Keeler JF, Robbins TW (2011) Translating cognition from animals to humans. Biochem Pharmacol 81:1356-1366

Kellendonk C, Simpson EH, Kandel ER (2009) Modeling cognitive endophenotypes of schizophrenia in mice. Trends Neurosci 32: 347-358

Kirsch P, Esslinger C, Chen Q, Mier D, Lis S, Siddhanti S, Gruppe H, Mattay VS, Gallhofer B, Meyer-Lindenberg A (2005) Oxytocin modulates neural circuitry for social cognition and fear in humans. J Neurosci 25:11489-11493

Kleber HD (2007) Pharmacologic treatments for opioid dependence: detoxification and maintenance options. Dialogues Clin Neurosci 9: $455-470$

Knutson B, Westdorp A, Kaiser E, Hommer D (2000) FMRI visualization of brain activity during a monetary incentive delay task. Neuroimage 12:20-27

Koblan KS, Hopkins S, Kent J, Cheng H, Goldman R, Loebel A (2020) 138 Efficacy and safety of SEP-363856, a novel psychotropic agent with a non-D2 mechanism of action, in the treatment of schizophrenia. CNS Spectr 25:287-288

Kokkinou M, Irvine EE, Bonsall DR, Natesan S, Wells LA, Smith M, Glegola J, Paul EJ, Tossell K, Veronese M, Khadayate S, Dedic N, Hopkins SC, Ungless MA, Withers DJ, Howes OD (2020) Reproducing the dopamine pathophysiology of schizophrenia and approaches to ameliorate it: a translational imaging study with ketamine. Mol Psychiatry. https://doi.org/10.1038/s41380-020-0740-6

Kose S, Cetin M (2017) Brexanolone: an allosteric modulator of GABAA receptors in the rapid treatment of postpartum depression. Psychiatry Clin Psychopharmacol 27:326-328

Kramer JH, Quitania L, Dean D, Neuhaus J, Rosen HJ, Halabi C, Weiner MW, Magnotta VA, Delis DC, Miller BL (2007) Magnetic 
resonance imaging correlates of set shifting. J Int Neuropsychol Soc 13:386-392

Krebs TS, Johansen PO (2012) Lysergic acid diethylamide (LSD) for alcoholism: meta-analysis of randomized controlled trials. J Psychopharmacol 26:994-1002

Krystal JH, Karper LP, Seibyl JP, Freeman GK, Delaney R, Bremner JD, Heninger GR, Bowers MB Jr, Charney DS (1994) Subanesthetic effects of the noncompetitive NMDA antagonist, ketamine, in humans. Psychotomimetic, perceptual, cognitive, and neuroendocrine responses. Arch Gen Psychiatry 51:199-214

Krystal JH, Anand A, Moghaddam B (2002) Effects of NMDA receptor antagonists: implications for the pathophysiology of schizophrenia. Arch Gen Psychiatry 59:663-664

Krystal JH, Abdallah CG, Sanacora G, Charney DS, Duman RS (2019) Ketamine: A Paradigm Shift for Depression Research and Treatment. Neuron 101:774-778

Krystal AD, Pizzagalli DA, Smoski M, Mathew SJ, Nurnberger J, Lisanby SH, Iosifescu D, Murrough JW, Yang H, Weiner RD, Calabrese JR, Sanacora G, Hermes G, Keefe RSE, Song A, Goodman W, Szabo ST, Whitton AE, Gao K, Potter WZ (2020) A randomized proof-of-mechanism trial applying the 'fast-fail' approach to evaluating K-opioid antagonism as a treatment for anhedonia. Nat Med 26:760-768

Kumar B, Kuhad A, Kuhad A (2018) Lumateperone: a new treatment approach for neuropsychiatric disorders. Drugs Today (Barc) 54: 713-719

Lahey BB, Applegate B, Hakes JK, Zald DH, Hariri AR, Rathouz PJ (2012) Is there a general factor of prevalent psychopathology during adulthood? J Abnorm Psychol 121:971-977

Lang UE, Bajbouj M, Gallinat J, Hellweg R (2006) Brain-derived neurotrophic factor serum concentrations in depressive patients during vagus nerve stimulation and repetitive transcranial magnetic stimulation. Psychopharmacology 187:56-59

Leeson VC, Robbins TW, Matheson E, Hutton SB, Ron MA, Barnes TR, Joyce EM (2009) Discrimination learning, reversal, and set-shifting in first-episode schizophrenia: stability over six years and specific associations with medication type and disorganization syndrome. Biol Psychiatry 66:586-593

Lepack AE, Bang E, Lee B, Dwyer JM, Duman RS (2016) Fast-acting antidepressants rapidly stimulate ERK signaling and BDNF release in primary neuronal cultures. Neuropharmacology 111:242-252

Li CS, Huang C, Constable RT, Sinha R (2006) Imaging response inhibition in a stop-signal task: neural correlates independent of signal monitoring and post-response processing. J Neurosci 26:186-192

Li J, Ishiwari K, Conway MW, Francois J, Huxter J, Lowry JP, Schwarz AJ, Tricklebank M, Gilmour G (2014) Dissociable effects of antipsychotics on ketamine-induced changes in regional oxygenation and inter-regional coherence of low frequency oxygen fluctuations in the rat. Neuropsychopharmacology 39:1635-1644

Li J, Schwarz AJ, Gilmour G (2016a) Relating translational neuroimaging and amperometric endpoints: utility for neuropsychiatric drug discovery. Curr Top Behav Neurosci 28:397-421

Li Y-W, Seager MA, Wojcik T, Heman K, Molski TF, Fernandes A, Langdon S, Pendri A, Gerritz S, Tian Y, Hong Y, Gallagher L, Merritt JR, Zhang C, Westphal R, Zaczek R, Macor JE, Bronson JJ, Lodge NJ (2016b) Biochemical and behavioral effects of PDE10A inhibitors: relationship to target site occupancy. Neuropharmacology 102:121-135

Liu W, Downing AC, Munsie LM, Chen P, Reed MR, Ruble CL, Landschulz KT, Kinon BJ, Nisenbaum LK (2012) Pharmacogenetic analysis of the mGlu2/3 agonist LY2140023 monohydrate in the treatment of schizophrenia. Pharm J 12:246-254

Lorrain DS, Baccei CS, Bristow LJ, Anderson JJ, Varney MA (2003) Effects of ketamine and N-methyl-D-aspartate on glutamate and dopamine release in the rat prefrontal cortex: modulation by a group
II selective metabotropic glutamate receptor agonist LY379268. Neuroscience 117:697-706

Lowry JP, Griffin K, Mchugh SB, Lowe AS, Tricklebank M, Sibson NR (2010) Real-time electrochemical monitoring of brain tissue oxygen: a surrogate for functional magnetic resonance imaging in rodents. Neuroimage 52:549-555

Lydall ES, Gilmour G, Dwyer DM (2010) Analysis of licking microstructure provides no evidence for a reduction in reward value following acute or sub-chronic phencyclidine administration. Psychopharmacology 209:153-162

Manzke T, Guenther U, Ponimaskin EG, Haller M, Dutschmann M, Schwarzacher S, Richter DW (2003) 5-HT4(a) receptors avert opioid-induced breathing depression without loss of analgesia. Science 301:226-229

Markou A, Chiamulera C, Geyer MA, Tricklebank M, Steckler T (2009) Removing obstacles in neuroscience drug discovery: the future path for animal models. Neuropsychopharmacology 34:74-89

Marsh AA, Finger EC, Fowler KA, Adalio CJ, Jurkowitz IT, Schechter JC, Pine DS, Decety J, Blair RJ (2013) Empathic responsiveness in amygdala and anterior cingulate cortex in youths with psychopathic traits. J Child Psychol Psychiatry 54:900-910

Medeiros GC, Greenstein D, Kadriu B, Yuan P, Park LT, Gould TD, Zarate CA (2021) Treatment of depression with ketamine does not change plasma levels of brain-derived neurotrophic factor or vascular endothelial growth factor. J Affect Disord 280:136-139

Meyer LC, Fuller A, Mitchell D (2006) Zacopride and 8-OH-DPAT reverse opioid-induced respiratory depression and hypoxia but not catatonic immobilization in goats. Am J Phys Regul Integr Comp Phys 290:R405-R413

Minett MS, Pereira V, Sikandar S, Matsuyama A, Lolignier S, Kanellopoulos AH, Mancini F, Iannetti GD, Bogdanov YD, Santana-Varela S, Millet Q, Baskozos G, Macallister R, Cox JJ, Zhao J, Wood JN (2015) Endogenous opioids contribute to insensitivity to pain in humans and mice lacking sodium channel Nav1.7. Nat Commun 6:8967

Moaddel R, Luckenbaugh DA, Xie Y, Villasenor A, Brutsche NE, Machado-Vieira R, Ramamoorthy A, Lorenzo MP, Garcia A, Bernier M, Torjman MC, Barbas C, Zarate CA Jr, Wainer IW (2015) D-serine plasma concentration is a potential biomarker of $(\mathrm{R}, \mathrm{S})$-ketamine antidepressant response in subjects with treatmentresistant depression. Psychopharmacology 232:399-409

Modi ME, Inoue K, Barrett CE, Kittelberger KA, Smith DG, Landgraf R, Young LJ (2015) Melanocortin receptor agonists facilitate oxytocindependent partner preference formation in the prairie vole. Neuropsychopharmacology 40:1856-1865

Mohler EG, Ding Z, Rueter LE, Chapin D, Young D, Kozak R (2015) Cross-site strain comparison of pharmacological deficits in the touchscreen visual discrimination test. Psychopharmacology 232: 4033-4041

Moieni M, Irwin MR, Jevtic I, Breen EC, Cho HJ, Arevalo JM, Ma J, Cole SW, Eisenberger NI (2015) Trait sensitivity to social disconnection enhances pro-inflammatory responses to a randomized controlled trial of endotoxin. Psychoneuroendocrinology 62:336-342

Mrazek DA, Hornberger JC, Altar CA, Degtiar I (2014) A review of the clinical, economic, and societal burden of treatment-resistant depression: 1996-2013. Psychiatr Serv 65:977-987

Nardou R, Lewis EM, Rothhaas R, Xu R, Yang A, Boyden E, Dolen G (2019) Oxytocin-dependent reopening of a social reward learning critical period with MDMA. Nature 569:116-120

Niesters M, Khalili-Mahani N, Martini C, Aarts L, VAN Gerven J, VAN Buchem MA, Dahan A, Rombouts S (2012) Effect of subanesthetic ketamine on intrinsic functional brain connectivity: a placebocontrolled functional magnetic resonance imaging study in healthy male volunteers. Anesthesiology 117:868-877

Nilsson SRO, Heath CJ, Takillah S, Didienne S, Fejgin K, Nielsen V, Nielsen J, Saksida LM, Mariani J, Faure P, Didriksen M, Robbins 
TW, Bussey TJ, Mar AC (2018) Continuous performance test impairment in a 22q11.2 microdeletion mouse model: improvement by amphetamine. Transl Psychiatry 8:247

Nutt D (2014) Help luck along to find psychiatric medicines. Nature 515: 165

Ondicova K, Pecenak J, Mravec B (2010) The role of the vagus nerve in depression. Neuro Endocrinol Lett 31:602-608

Oya K, Matsuda Y, Matsunaga S, Kishi T, Iwata N (2016) Efficacy and safety of oxytocin augmentation therapy for schizophrenia: an updated systematic review and meta-analysis of randomized, placebocontrolled trials. Eur Arch Psychiatry Clin Neurosci 266:439-450

Parmentier-Batteur S, Hutson PH, Menzel K, Uslaner JM, Mattson BA, O'brien JA, Magliaro BC, Forest T, Stump CA, Tynebor RM, Anthony NJ, Tucker TJ, Zhang XF, Gomez R, Huszar SL, Lambeng N, Fauré H, LE Poul E, Poli S, Rosahl TW, Rocher JP, Hargreaves R, Williams TM (2014) Mechanism based neurotoxicity of mGlu5 positive allosteric modulators-development challenges for a promising novel antipsychotic target. Neuropharmacology 82:161-173

Patel V, Saxena S, Lund C, Thornicroft G, Baingana F, Bolton P, Chisholm D, Collins PY, Cooper JL, Eaton J, Herrman H, Herzallah MM, Huang Y, Jordans MJD, Kleinman A, MedinaMora ME, Morgan E, Niaz U, Omigbodun O, Prince M, Rahman A, Saraceno B, Sarkar BK, DE Silva M, Singh I, Stein DJ, Sunkel C, Unutzer J (2018) The Lancet Commission on global mental health and sustainable development. Lancet 392:1553-1598

Pelechas E, Voulgari PV, Drosos AA (2017) Sirukumab: a promising therapy for rheumatoid arthritis. Expert Opin Biol Ther 17:755-763

Penalver Bernabe B, Maki PM, Dowty SM, Salas M, Cralle L, Shah Z, Gilbert JA (2020) Precision medicine in perinatal depression in light of the human microbiome. Psychopharmacology 237:915-941

Phillips JL, Norris S, Talbot J, Hatchard T, Ortiz A, Birmingham M, Owoeye O, Batten LA, Blier P (2020) Single and repeated ketamine infusions for reduction of suicidal ideation in treatment-resistant depression. Neuropsychopharmacology 45:606-612

Pihl RO, Lemarquand D (1998) Serotonin and aggression and the alcohol-aggression relationship. Alcohol Alcohol 33:55-65

Plichta MM, Schwarz AJ, Grimm O, Morgen K, Mier D, Haddad L, Gerdes AB, Sauer C, Tost H, Esslinger C, Colman P, Wilson F, Kirsch P, Meyer-Lindenberg A (2012) Test-retest reliability of evoked BOLD signals from a cognitive-emotive fMRI test battery. Neuroimage 60:1746-1758

Porteous DJ, Millar JK, Brandon NJ, Sawa A (2011) DISC1 at 10: connecting psychiatric genetics and neuroscience. Trends Mol Med 17:699-706

Reagan LP, Hendry RM, Reznikov LR, Piroli GG, Wood GE, Mcewen BS, Grillo CA (2007) Tianeptine increases brain-derived neurotrophic factor expression in the rat amygdala. Eur.J Pharmacology 2268-2275

Robbins TW, Moore HM (2008) Modeling psychiatric disorders in experimental animals. In: Tasman A, Kay J, Lieberman JA, First MB, Maj M (eds) Psychiatry, 3rd edn. Wiley-Blackwell, West Sussex

Rubia K, Halari R, Cubillo A, Mohammad A-M, Brammer M, Taylor E (2009) Methylphenidate normalises activation and functional connectivity deficits in attention and motivation networks in medication-naïve children with $\mathrm{ADHD}$ during a rewarded continuous performance task. Neuropharmacology 57:640-652

Rupniak NM, Boyce S, Tye S, Cook G, Iversen SD (1993) Anxiolyticlike and antinociceptive effects of MK-801 accompanied by sedation and ataxia in primates. Pharmacol Biochem Behav 44:153-156

Sakurai M, Yamamoto Y, Kanayama N, Hasegawa M, Mouri A, Takemura M, Matsunami H, Miyauchi T, Tokura T, Kimura H, Ito M, Umemura E, Boku AS, Nagashima W, Tonoike T, Kurita K, Ozaki N, Nabeshima T, Saito K (2020) Serum metabolic profiles of the tryptophan-kynurenine pathway in the high risk subjects of major depressive disorder. Sci Rep 10:1961
Salomon R, Bleich-Cohen M, Hahamy-Dubossarsky A, Dinstien I, Weizman R, Poyurovsky M, Kupchik M, Kotler M, Hendler T, Malach R (2011) Global functional connectivity deficits in schizophrenia depend on behavioral state. J Neurosci 31:12972-12981

Sarter M, Tricklebank M (2012) Revitalising Psychiatric drug discovery. Nat Rev Drug Discov 114:423-424

Scarpa JR, Fatma M, Loh Y-HE, Traore SR, Stefan T, Chen TH, Nestler EJ, Labonté B (2020) Shared transcriptional signatures in major depressive disorder and mouse chronic stress models. Biol Psychiatry 88:159-168

Selzam S, Coleman JRI, Caspi A, Moffitt TE, Plomin R (2018) A polygenic $\mathrm{p}$ factor for major psychiatric disorders. Transl Psychiatry 8: 205

Sheikhmoonesi F, Zarghami M, Bahari Saravi SF, Khalilian A, Ala S (2015) A triple-blinded, randomized, placebo-controlled trial to examine the efficacy of buspirone added to typical antipsychotic drugs in patients with chronic schizophrenia. J Res Med Sci 20:140-145

Shirayama Y, Fujita Y, Oda Y, Iwata M, Muneoka K, Hashimoto K (2020) Allopregnanolone induces antidepressant-like effects through BDNF-TrkB signaling independent from AMPA receptor activation in a rat learned helplessness model of depression. Behav Brain Res 390:112670

Singh L, Oles RJ, Tricklebank MD (1990) Modulation of seizure susceptibility in the mouse by the strychnine-insensitive glycine recognition site of the NMDA receptor/ion channel complex. Br J Pharmacol 99:285-288

Siskind D, Siskind V, Kisely S (2017) Clozapine response rates among people with treatment-resistant schizophrenia: data from a systematic review and meta-analysis. Can J Psychiatr 62:772-777

Siuciak JA, Boylan C, Fritsche M, Altar CA, Lindsay RM (1996) BDNF increases monoaminergic activity in rat brain following intracerebroventricular or intraparenchymal administration. Brain Res 710:11-20

Sorensen SM, Kehne JH, Fadayel GM, Humphreys TM, Ketteler HJ, Sullivan CK, Taylor VL, Schmidt CJ (1993) Characterization of the 5-HT2 receptor antagonist MDL 100907 as a putative atypical antipsychotic: behavioral, electrophysiological and neurochemical studies. J Pharmacol Exp Ther 266:684-691

Souza RP, DE Luca V, Meltzer HY, Lieberman JA, Kennedy JL (2010) Schizophrenia severity and clozapine treatment outcome association with oxytocinergic genes. Int J Neuropsychopharmacol 13:793-798

Steiner J, Walter M, Gos T, Guillemin GJ, Bernstein HG, Sarnyai Z, Mawrin C, Brisch R, Bielau H, Meyer Zu Schwabedissen L, Bogerts B, Myint AM (2011) Severe depression is associated with increased microglial quinolinic acid in subregions of the anterior cingulate gyrus: evidence for an immune-modulated glutamatergic neurotransmission? J Neuroinflammation 8:94

Stensbol TB, Kapur S (2015) NEWMEDS special issue commentary. Psychopharmacology 232:3849-3851

Stock S, Uvnas-Moberg K (1988) Increased plasma levels of oxytocin in response to afferent electrical stimulation of the sciatic and vagal nerves and in response to touch and pinch in anaesthetized rats. Acta Physiol Scand 132:29-34

Stone EA, Lin Y, Quartermain D (2008) A final common pathway for depression? Progress toward a general conceptual framework. Neurosci Biobehav Rev 32:508-524

Tampi RR, Tampi DJ, Young JJ, Balachandran S, Hoq RA, Manikkara G (2019) Evidence for using pimavanserin for the treatment of Parkinson's disease psychosis. World J Psychiatry 9:47-54

Teixeira AL, Rocha NP, Zhang X (2017) Anti-NMDAR antibodies as a new piece in schizophrenia's puzzle. Future Sci OA 3:FSO178

Tricklebank MD, Ajram L (2017) Why is pharma so scared of psychiatric drug discover. Integrative Neurosci Res 1(1):1-4

Trullas R, Skolnick P (1990) Functional antagonists at the NMDA receptor complex exhibit antidepressant actions. Eur J Pharmacol 185:1-10 
Uysal N, Camsari UM, M AT, Kandis S, Karakilic A, Camsari GB (2020) Empathy as a Concept from Bench to Bedside: A Translational Challenge. Noro Psikiyatr Ars 57:71-77

Vaghi MM, Vertes PE, Apergis-Schoute AM, vanderflier FE, Fineberg NA, Sule A, Zaman R, Voon V, Kundu P, Bullmore ET, Robbins TW (2017) Specific frontostriatalCircuits for impaired cognitive flexibility and goal directed planning in Obsessive-Compulsive disorder:evidence from resting state functional connectivity. Biol Psychiatry 81:708-717

Vollenweider FX, Kometer M (2010) The neurobiology of psychedelic drugs: implications for the treatment of mood disorders. Nat Rev Neurosci 11:642-651

Westbrook A, VAN DEN Bosch R, Maatta JI, Hofmans L, Papadopetraki D, Cools R, Frank MJ (2020) Dopamine promotes cognitive effort by biasing the benefits versus costs of cognitive work. Science 367 : $1362-1366$

Windrem MS, Osipovitch M, Liu Z, Bates J, Chandler-Militello D, Zou L, Munir J, Schanz S, Mccoy K, Miller RH, Wang S, Nedergaard M, Findling RL, Tesar PJ, Goldman SA (2017) Human iPSC Glial Mouse Chimeras Reveal Glial Contributions to Schizophrenia. Cell Stem Cell 21:195-208 e6

Wong EH, Yocca F, Smith MA, Lee CM (2010) Challenges and opportunities for drug discovery in psychiatric disorders: the drug hunters' perspective. Int J Neuropsychopharmacol 13:1269-1284
Xia CH, Ma Z, Ciric R, Gu S, Betzel RF, Kaczkurkin AN, Calkins ME, Cook PA, Garcia De La Garza A, Vandekar SN, Cui Z, Moore TM, Roalf DR, Ruparel K, Wolf DH, Davatzikos C, Gur RC, Gur RE, Shinohara RT, Bassett DS, Satterthwaite TD (2018) Linked dimensions of psychopathology and connectivity in functional brain networks. Nat Commun 9:3003

Zanos P, Moaddel R, Morris PJ, Riggs LM, Highland JN, Georgiou P, Pereira EFR, Albuquerque EX, Thomas CJ, Zarate CA Jr, Gould TD (2018) Ketamine and ketamine metabolite pharmacology: insights into therapeutic mechanisms. Pharmacol Rev 70:621-660

Zarate CA Jr, Singh JB, Carlson PJ, Brutsche NE, Ameli R, Luckenbaugh DA, Charney DS, Manji HK (2006) A randomized trial of an Nmethyl-D-aspartate antagonist in treatment-resistant major depression. Arch Gen Psychiatry 63:856-864

Zhou AJ, Lee Y, Salvadore G, Hsu B, Fonseka TM, Kennedy SH, Mcintyre RS (2017) Sirukumab: a potential treatment for mood disorders? Adv Ther 34:78-90

Publisher's note Springer Nature remains neutral with regard to jurisdictional claims in published maps and institutional affiliations. 